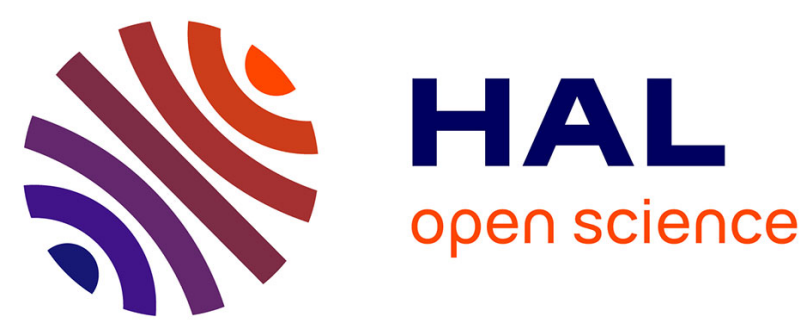

\title{
Experimental and numerical study of crack healing in a nuclear glass
}

Véronique Doquet, N. Ben Ali, E Chabert, F Bouyer

\section{To cite this version:}

Véronique Doquet, N. Ben Ali, E Chabert, F Bouyer. Experimental and numerical study of crack healing in a nuclear glass. Mechanics of Materials, 2014, 80, pp.145-162. 10.1016/j.mechmat.2014.09.003 . hal-01082803

\section{HAL Id: hal-01082803 \\ https://hal.science/hal-01082803}

Submitted on 14 Nov 2014

HAL is a multi-disciplinary open access archive for the deposit and dissemination of scientific research documents, whether they are published or not. The documents may come from teaching and research institutions in France or abroad, or from public or private research centers.
L'archive ouverte pluridisciplinaire HAL, est destinée au dépôt et à la diffusion de documents scientifiques de niveau recherche, publiés ou non, émanant des établissements d'enseignement et de recherche français ou étrangers, des laboratoires publics ou privés. 


\section{Accepted Manuscript}

Experimental and numerical study of crack healing in a nuclear glass

V. Doquet, N. Ben Ali, E. Chabert, F. Bouyer

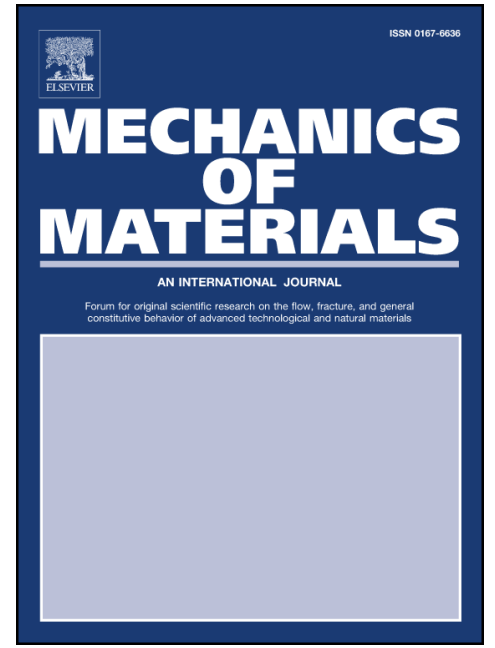

PII: S0167-6636(14)00166-5

DOI: http://dx.doi.org/10.1016/j.mechmat.2014.09.003

Reference: MECMAT 2317

To appear in: Mechanics of Materials

Received Date: 17 March 2014

Revised Date: 6 September 2014

Please cite this article as: Doquet, V., Ben Ali, N., Chabert, E., Bouyer, F., Experimental and numerical study of crack healing in a nuclear glass, Mechanics of Materials (2014), doi: http://dx.doi.org/10.1016/j.mechmat. 2014.09.003

This is a PDF file of an unedited manuscript that has been accepted for publication. As a service to our customers we are providing this early version of the manuscript. The manuscript will undergo copyediting, typesetting, and review of the resulting proof before it is published in its final form. Please note that during the production process errors may be discovered which could affect the content, and all legal disclaimers that apply to the journal pertain. 


\title{
Experimental and numerical study of crack healing in a nuclear glass
}

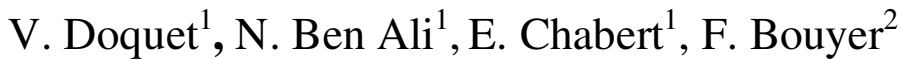

1 : Laboratoire de Mécanique des Solides, CNRS, Ecole Polytechnique, 91128 Palaiseau cedex, France

2 : CEA Marcoule, DTCD SECM, Bagnols-sur-Cèze, France

Corresponding author: doquet@lms.polytechnique.fr, 331693357 65, fax: 33169335706

\begin{abstract}
An experimental study of thermally or water-induced crack healing in an inactive borosilicate glass, chemically analogous to that used in France for the vitrification of nuclear waste was carried out. Partial welding of glass plates was observed after annealing in air at $425^{\circ} \mathrm{C}\left(77^{\circ} \mathrm{C}\right.$ below $\mathrm{T}_{\mathrm{g}}$ ) when at least $20 \mathrm{MPa}$ compressive stress was applied, while annealing at $450^{\circ} \mathrm{C}$ under $20 \mathrm{MPa}$ led to a complete disappearance of the interface. Closure of indentation-induced cracks was observed during annealing at $400^{\circ} \mathrm{C}$ in an ESEM as a result of viscous relaxation of residual stresses but it did not constitute a sufficient proof of crack healing. DCDC specimens were thus precracked in an ESEM and then either annealed at various temperatures (350 to $490^{\circ} \mathrm{C}$ ) in secondary vacuum or in air, or left in water at $70^{\circ} \mathrm{C}$ to $90^{\circ} \mathrm{C}$, sometimes under a compressive stress normal to the crack face. The specimens were then reloaded in the ESEM and the crack opening displacements under a given load were compared to those measured during pre-cracking. The cracks were bridged by an alteration layer over a distance from the crack tip which decreased as loading increased. Tthe restraining effect of these bridges on crack opening was assessed via finite element simulations, using interface elements. The tensile strength of the bridging layer was estimated as $27-39 \mathrm{Mpa}$ after vacuum annealing at $400^{\circ} \mathrm{C}, 11-20 \mathrm{MPa}$ after 15 days in water at $90^{\circ} \mathrm{C}$ and $44-78 \mathrm{MPa}$ after 11 days in water at $70^{\circ} \mathrm{C}$ under $5 \mathrm{MPa}$ normal compression. Partially healed cracks did not resume propagation from their former crack tip, but due to branch cracks re-initiated a few hundred microns behind it which grow avoiding the healed area. This behaviour was explained using finite element simulations.
\end{abstract}

Keywords: glass; crack; healing; moisture; nuclear waste; adhesion

\section{Introduction}

\section{I.A. Context of the study.}

In a French reprocessing plant, large blocks of vitrified nuclear waste for underground disposal are prepared by pouring a mixture of crushed high-activity waste and molten borosilicate glass into steel canisters. Upon cooling, cracks may develop due to thermal gradients. This problem has been investigated in previous studies (Dubé et al. 2010, Doquet et al. 21013). However, since the radionuclides constitute an internal heat source and since several canisters are initially stored in the same room, the temperature inside the glass blocks remains high during a long period (above $400{ }^{\circ} \mathrm{C}$ during the first day and above $350^{\circ} \mathrm{C}$ during three years, according to Barth et al. 2012), so that 
thermally-induced healing of the cracks can be expected, at least partially. An experimental and numerical study of thermally-induced crack healing in an inactive borosilicate glass, chemically analogous to the industrial product was therefore undertaken.

Another issue to address is that of long-range behaviour: even though the glass block temperature will eventually drop below $90^{\circ} \mathrm{C}$ (due to radioactive decay), water will at a time be able to reach the glass blocks. In addition, the galleries may collapse, so that the glass block will also be submitted to a lithostatic compression.

All this might trigger subcritical growth of some of the pre-existing cracks, more precisely those submitted to a sufficient mode I loading. Many studies in the literature have already been devoted to this topic. At the same time, the new sollicitations might also heal those among the cracks that will be submitted to a normal compression or even to a weak mode I loading below the subcritical crack growth threshold. Contrary to the former "damaging" scenario, the latter has hardly been considered so far. That is why an investigation of water-induced and mechanically-assisted crack healing at 70 to $90^{\circ} \mathrm{C}$ was also undertaken.

Before describing this study and its results, a survey of the literature devoted to crack healing phenomena in glasses, at high or low temperatures will first be presented.

\section{I.B. literature on thermally-induced crack healing in glasses around $\mathrm{Tg}$}

Thermally-induced healing of indentation-induced cracks in transparent soda-lime glass annealed at $650^{\circ} \mathrm{C}$ has been observed by Hrma et al.(1988). The process was attributed to "capillarity-driven viscous flow" and the adimensional variable $\frac{t \mu}{\eta}$-where t stands for the annealing time, $\mu$ for the shear modulus and $\eta$ for viscosity- was considered as a controlling parameter.

Hirao \& Tomozawa (1987) annealed various types of glass near their glass-transition temperature, in air or vacuum, and found that annealing in moist air is much more efficient for strength recovery of indentation-precracked specimens. They attributed this recovery to viscous flow-induced crack tip blunting, made easier by moisture since, as shown by Bartolomew (1983), water absorption reduces the viscosity of glass. Crack tip blunting suppresses the stress singularity at the crack tip and thus explains the strength recovery.

This phenomenon was later confirmed by Atomic Force Microscope (AFM) measurements by Kese et al. (2006).

Girard et al (2011) reached similar conclusions as those of Hirao and Tomozawa concerning the lowering of viscosity by water and the enhancement of crack healing.

Holden and Fréchette (1989) also concluded that a certain degree of moisture is necessary for crack healing in soda-lime-silica glass annealed at $550^{\circ} \mathrm{C}$ and that a compressive stress assists selfwelding of contacting glass plates during annealing, provided that it is not so high that it prevents moisture from reaching the interface, if the stress is applied before the temperature rise. 
This argument seems questionable, since, according to the kinetic data from D'Souza and Pantano (2002), water was probably already adsorbed on the surface of their specimens (kept in air before annealing). Due to surface roughness, which leaves empty space for water in-between the contacting surfaces, a compressive stress might even be suspected to trap water instead of preventing its access.

Wilson and Case (1997) investigated thermally-induced healing of indentation-induced cracks in borosilicate glass by direct ESEM observations during short in situ annealing. They reported crack tip regression or crack pinch-off at discrete points along the crack. They varied the initial moisture content in the ESEM chamber during annealing (Wilson and Case 1999) and concluded that a higher moisture allows crack healing at a lower temperature (as low as $370^{\circ} \mathrm{C}$ in borosilicate glass for a moisture level $\mathrm{RH}=64 \%$ ).

Similar in situ observations were also performed by Méar et al. (2011) who found that healing starts when the temperature approaches the softening temperature, $T_{s}$, for which the viscosity of the glass drops to $10^{11}$ Poise. In the glasses used to seal solid oxide fuel cells that they investigated, $\mathrm{T}_{\mathrm{s}}$ was 60 to $65^{\circ} \mathrm{C}$ above $\mathrm{T}_{\mathrm{g}}$ (for which the viscosity is $10^{13}$ Poise).

A linear relationship between the time necessary for complete crack healing and glass viscosity was deduced from optical monitoring of indentation-induced cracks during high temperature annealing of silicate glass by Sing and Parihar (2009). They developed a predictive model based on a threestage process: 1) crack tip blunting and some other morphological changes, which results in cylinderization of the crack, 2) filling of the cylindrical cavity, which results in spheroidization and 3) filling of the spherical cavity, which results in a crack-free surface. They also considered the softening temperature of the glass as a threshold temperature for thermally-induced crack healing.

\section{I.C. Literature on low-temperature crack healing in glasses}

Cheeseman and Lawn (1970) achieved partial healing of Hertzian cone cracks in an unspecified type of glass, by low temperature annealing $\left(200^{\circ} \mathrm{C}\right)$ in nitrogen and even at room temperature, under the mere effect of a compressive stress.

Widerhorn and Townsend (1970) reported a more complete room temperature healing of cracks induced in soda-lime-silica glass by mechanical shock in a superdry nitrogen atmosphere than that of cracks grown in air. They attributed this difference to a reduction in chemical activity of fracture surfaces by adsorbed $\mathrm{H}_{2} \mathrm{O}$ and $\mathrm{O}_{2}$.

Michalske and Fuller (1985) measured the energy release rate, $G_{r}$, corresponding to re-opening of "healed" cracks (as they call cracks kept closed for 5 minutes at room temperature in various environments with controlled moisture) in vitreous silica and soda-lime silica glass. They suggested that hydrogen bonding of water molecules adsorbed on crack surfaces is sufficient to pull crack surfaces together and cause crack closure in silica or soda lime glass while a finite load is still being applied. Due to its relatively long range, hydrogen bonding would be the first interaction to take place, while the cracks are progressively closing. For soda-lime glass, they report the highest $\mathrm{G}_{\mathrm{r}}$ in the driest conditions, which they attribute either to bridging between $\mathrm{SiO}^{-}$groups by surface- 
adsorbed cations, or to the formation of bridging siloxane bonds by the condensation of surface silanol groups.

Stavrinidis and Holloway (1983) also found that for soda-lime or borosilicate glasses $\mathrm{G}_{\mathrm{r}}$ is highest for cracks closed and treated in relatively dry environments.

\section{I.D. Open questions and present study}

From this literature survey, crack healing in glasses appears to involve coupled mechanical, physical and chemical phenomena that are not completely understood.

First, the threshold temperature above which thermally-induced healing is likely to occur in glasses is not clearly defined: it varies from $370^{\circ} \mathrm{C}$-nearly $130^{\circ} \mathrm{C}$ below $\mathrm{Tg}$ - according to Wilson and Case (1997, 1999) up to $65^{\circ} \mathrm{C}$ above Tg, according to Mear (2001) or Sing and Parihar (2009) !

In the context of cooling nuclear glass, the temperature of interest (down to $162{ }^{\circ} \mathrm{C}$ below $\mathrm{Tg}$ ) is significantly smaller than that of most studies mentioned above while the time scale (days and even years) is much larger than the annealing times used in most studies, ranging from a few minutes to a few hours. Crack healing in such unusual conditions is thus worth investigating. Since the environment of the cracks that are likely to heal in nuclear waste blocks is not clear, both air and vacuum annealing were investigated in the present study. On the one hand, internal cracks -except those connected to the surface through the crack network- do not interact with ambient air, so that vacuum annealing might be considered representative of their condition, on the other hand, the cracks tend to initiate from pores - formed due to argon bubbling for homogenization of the molten mixture- as shown in (Doquet et al. 2013). The moisture content of the gas trapped in those pores is not known, so that annealing in moist air should also be investigated.

Second, if moisture seems to assist thermally-induced healing around $\mathrm{Tg}$, it is rather considered as detrimental to crack healing at low temperature. While subcritical crack growth as well as surface alteration in aqueous environment have been widely investigated in nuclear glass, natural or mechanically-assisted healing in water has not. That is why a part of this study was devoted to this question.

\section{Experimental procedures}

The material investigated is an opaque borosilicate glass (major constituents in weight: $44.3 \% \mathrm{SiO}_{2}$, $13.3 \% \mathrm{~B}_{2} \mathrm{O}_{3}, 9.2 \% \mathrm{Na}_{2} \mathrm{O}$ plus many other elements, among which Ruthenium and Palladium that emulate -from a chemical point of view- some heavy radionuclides). It also contains more or less spherical pores, as mentioned above. More details on the microstructure and thermo-mechanical properties of this glass whose $\mathrm{T}_{\mathrm{g}}$ is $502^{\circ} \mathrm{C}$ can be found in (Dubé et al. 2010, Doquet et al. 2013, Barth et al 2012).

Three types of experiments were carried out: 1) annealing of two contacting glass plates, with or without a compressive stress, 2) in-situ annealing of indentation-initiated cracks in an environmental scanning electron microscope (ESEM) and 3) crack healing experiments using Double Cleavage Drilled Compression (DCDC) specimens loaded in compression in an ESEM before and after healing treatments. 
The first type of experiments was done on $15^{*} 15^{*} 2 \mathrm{~mm}$, polished to $1 \mu \mathrm{m}$. The desired temperature was reached in 180 minutes and kept constant during 250 minutes before natural cooling in the oven with power switched off. In some cases, a compressive stress was applied during the temperature dwell period. Most tests were performed in air, except one, in secondary vacuum. In the cases where adhesion between the two plates was obtained after cooling, cross sections were polished and the aspect of the interface was observed under a digital optical microscope or the ESEM.

For the second type of experiments, $1 \mathrm{~mm}$-thick disk-shaped specimens, $3 \mathrm{~mm}$ in diameter were polished down to $1 \mu \mathrm{m}$ grade. Cracks were initiated near the centre, by Knoop indentation, with a load of $2 \mathrm{Kg}$. The pre-cracked specimens were then placed in a heating stage in the ESEM in "lowvacuum mode" (residual air pressure of $1.2 \mathrm{mBar}$ ) and heated in 10 minutes to $400^{\circ} \mathrm{C}$. This temperature was then kept constant and pictures of the crack were captured at intervals.

$7,5 * 7,5 * 75 \mathrm{~mm}$ DCDC specimens with a through hole, $2 \mathrm{~mm}$ in diameter at mid-height and one face polished to allow ESEM observations were used. He et al. (1995) provided an analytical expression of $\mathrm{K}_{\mathrm{I}}$ for this specimen geometry as:

$$
K_{I}=\frac{\sigma \sqrt{\pi R}}{\frac{w}{R}+\left(0.235 \frac{w}{R}-0.259\right) \frac{a}{R}}
$$

where $\sigma, \mathrm{w}, \mathrm{R}$ and a are respectively the compressive stress, the specimen width, the hole radius and the crack length. The decrease in $\mathrm{K}_{\mathrm{I}}$ as the crack length increases leads to stable crack growth and thus allows controlled pre-cracking.

Pre-cracking was performed using a tension-compression stage with a load range of $\pm 5 \mathrm{KN}$ in an ESEM under secondary vacuum (less than $10^{-3} \mathrm{~Pa}$ residual pressure), which nearly suppressed moisture-induced subcritical crack growth. In these conditions, the pre-crack length under a given compressive stress can be found by equating $\mathrm{K}_{\mathrm{I}}$ to the toughness, $\mathrm{K}_{\mathrm{IC}}$ in eq. 1 . This equality was approximately satisfied for all the tests mentioned below.

High- resolution ( $4048 * 4048$ pixels) digital images of the crack were captured under specific loads. Using these images, the crack opening displacement (COD) was measured as a function of the position along the crack face. With the magnification used, one pixel corresponds to $0.125 \mu \mathrm{m}$.

To investigate thermally-induced crack healing and the influence of moisture, the specimens were annealed either in air or under secondary vacuum. A few specimens were annealed in air with a compressive stress applied normal to the crack face. A total of 13 thermally-induced crack healing tests on DCDC specimens were done but only a few representative examples are detailed below for sake of brevity.

To investigate water-induced crack healing at low temperatures, two specimens were left during 15 days at $90^{\circ} \mathrm{C}$ in a solution saturated with $\mathrm{Na}, \mathrm{Si}$ and $\mathrm{B}-\mathrm{pH} \approx 9$ - and one specimen during 11 days in the same solution at $70^{\circ} \mathrm{C}$, with a $5 \mathrm{MPa}$ compression normal to the crack face. 
After both kinds of healing treatments, the specimens were brought back into the ESEM and resubmitted to in situ compression. The COD profiles were measured again and compared to those obtained under the same loads before the healing treatment. If healing occurred, this would reduce the COD at least at moderate loads for which the material bridging the crack would be intact. After the measurements, the cracks were propagated until complete separation of the specimens to allow SEM or optical observations of fracture surfaces.

\section{Experimental results}

\section{III.1. Thermally-induced and mechanically assisted welding of glass plates.}

Figure 1 delineates the domain where welding was obtained in a stress-temperature plane. At $400^{\circ} \mathrm{C}$ $\left(102^{\circ} \mathrm{C}\right.$ below $\left.\mathrm{T}_{\mathrm{g}}\right)$, no welding was obtained, even with $40 \mathrm{MPa}$ compression. At $425^{\circ} \mathrm{C}\left(77^{\circ} \mathrm{C}\right.$ below $\mathrm{T}_{\mathrm{g}}$, $450{ }^{\circ} \mathrm{C}$ and $490^{\circ} \mathrm{C}$, welding was obtained only when at least $20 \mathrm{MPa}$ compression was applied. No difference was observed when the $20 \mathrm{MPa}$ compressive stress was applied from the beginning of the temperature rise or only during the temperature dwell period at $425^{\circ} \mathrm{C}$ : both treatments induced specimens welding. Annealing in secondary vacuum without any compression did not induce welding even at $490^{\circ} \mathrm{C}$.

SEM observations of polished section of plates welded at $450^{\circ} \mathrm{C}$ under $20 \mathrm{MPa}$ reveal a complete disappearance of the interface. By contrast, Figure 2 which shows a section of plates welded at $425^{\circ} \mathrm{C}$ under $20 \mathrm{MPa}$ reveals that the interface disappeared only over approximately one third of the width, in the centre, not near side surfaces, where imperfectly-bonded parts remained (fig. 2a). A closer examination of the interface showed that near side surfaces (fig. 2b,c,d) it seemed to be filled with matter, sometimes rather compact (fig. 2c) and sometimes forming "filaments" (fig. 2d) and in some other portions empty gaps remain. Going towards the centre, the interface lookeed like a dotted line (fig. 2e), very similar to a partially healed crack with pinched off portions, as shown below.

\section{III.2. In situ-annealing of indentation-initiated cracks}

Figure 3 compares the aspect of an indentation crack before and after $4 \mathrm{~h} 20$ in situ annealing at $400^{\circ} \mathrm{C}$, under a residual air pressure of $120 \mathrm{~Pa}(1.2 \mathrm{mBar})$. Closure of the crack can be observed. However, crack closure might simply be due to viscous relaxation of the tensile residual stresses left by indentation which, added to the compaction of the glass below the indenter, were responsible for the initial residual opening of the crack. Stress relaxation tests performed at different temperatures during ring-on-ring bending tests on the same glass suggest that at $400^{\circ} \mathrm{C}$, at least partial stress relaxation can be expected within $4 \mathrm{~h} 20$. Such observations were thus not considered as conclusive proofs of crack healing, which should rather be evaluated by mechanical measurements. Furthermore, the presence of residual stresses and compaction in indented plates, as well as the 3D shape and multiplicity of indentation cracks -difficult to evaluate in an opaque glass- complicate the study of crack healing and may lead to misinterpretation of observations. In principle, such 
complicating factors are not present in pre-cracked DCDC specimens, which were thus preferred for further study.

\section{III.3. Crack healing in DCDC specimens}

\section{III.3.a. specimens annealed in secondary vacuum}

After $20 \mathrm{~h}$ annealing under secondary vacuum, bridges, a few microns to a hundred microns-long, with a concave meniscus shape at their extremities were formed between the crack face (figure $4 \mathrm{a}$, b). The length of these bridges tended to increase, going from the crack-starter hole, where the residual opening was highest, towards the crack tip where the opening was not measurable. A very small load $(390 \mathrm{~N}$, corresponding to a stress intensity factor of approximately $0.069 \mathrm{MPa} \sqrt{\mathrm{m}}$ according to eq. 1) was sufficient to break these bridges or to detach them from one crack face.

The bridges in the specimen annealed $216 \mathrm{~h}$ seemed much more compliant. Figure $4 \mathrm{c}$ to e shows the evolution of a bridged portion of the crack while loading was progressively increased. The bridges progressively shrunk but some parts were able to accommodate the crack opening and withstand up to $150 \%$ elongation, without fracture or detachment. One such bridge was still intact at $3450 \mathrm{~N}$ $(0.735 \mathrm{MPa} \sqrt{ } \mathrm{m})$ in an area where the crack opening reaches $1.75 \mu \mathrm{m}$ (Fig. $4 \mathrm{f})$.

Figure 5 shows the measured profiles of crack opening displacement (COD) at various loads in a DCDC specimen before and after $240 \mathrm{~h}$ vacuum anneal at $400^{\circ} \mathrm{C}$. The spatial resolution of the images (chosen so as to keep the number of images to stitch to cover the whole crack length reasonable) did not allow us to measure the COD values smaller than $0.1 \mu \mathrm{m}$ that can be found close to the crack tip at small loads. A zero COD after annealing means that a bridge was locally present. As can be seen on Figure 5b, there was less and less areas where the COD was zero as loading increased, but some bridges were still efficient at $1800 \mathrm{~N}$. A quantitative analysis of those data will be presented below.

One specimen was annealed during $120 \mathrm{~h}$ at $470^{\circ} \mathrm{C}$, with an accidental overshoot of the temperature during approximately $2 \mathrm{~h} 30$ to $490^{\circ} \mathrm{C}$ during the temperature rise. Crack tip regression was observed (Figure 6). Only a row of circular "dots" remained visible over the last 30 microns. The dark contrast surrounding the crack was attributed to capillary grooving as observed by Kese et al (2006) as well as by Hrma et al. (1988). When the DCDC specimen was loaded, the healed portion did not open. Finally, at $3600 \mathrm{~N}$ ( $86 \%$ of the load applied for pre-cracking) a branch crack initiated $280 \mu \mathrm{m}$ behind the initial crack tip and grew, avoiding the healed area.

A pre-cracked DCDC specimen was vacuum-annealed at $490^{\circ} \mathrm{C}$ during 250 minutes. A similar behaviour was observed: regression of the crack tip, no opening under load, but initiation of a branch crack from behind the previous tip at $74 \%$ of the pre-cracking load.

On the fracture surface of the specimen vacuum annealed $20 \mathrm{~h}$ at $400^{\circ} \mathrm{C}$ features evoking inward growth of a new phase were noticed near the side surfaces (Figure 7a). This suggests that mass 
transport during crack healing did not occur only along the crack growth direction and should be considered as a $3 \mathrm{D}$ process.

For longer annealing times, a clear and probably crystalline phase (considering its dendritic aspect, fig. 7c) was observed to grow preferentially from side surfaces (Fig. 7e), from pores (fig. 7b) and from crack front markings (Fig. 7d), in other words: from geometrical singularities. Attempts to analyse the chemical composition of this phase with an energy dispersive spectrometry device in a SEM were not successful, due to its very small thickness, with respect to the depth of the analyzed volume.

Raman analyses were performed with a Jobin Yvon Aramis spectrometer, coupled with a Nd:YAG laser at $532 \mathrm{~nm}$, in order to determine the composition of this new phase. Several filters were tested as well as different holes and splits for the laser to get rid of all possible bias and the CrystalSleuth software was used to interpret the data. The spectra collected for the dendritic phase were reproducible and quite different from that of the surrounding vitreous matrix. But no correspondence with any of the 7000 minerals spectra referenced in the RRUFF database (Downs 2006) could be found.

\section{III.3.b. specimens annealed in air}

Since Wilson and Case (1999) mentioned that in presence of moisture crack healing begins at lower temperatures than in vacuum, a specimen was annealed $339 \mathrm{~h}$ in air at $350^{\circ} \mathrm{C}$. However, no significant change in crack appearance was noticed in the ESEM and the measured COD profiles at a given load before and after annealing were similar, within experimental scatter.

Annealing at $400^{\circ} \mathrm{C}$ during $209 \mathrm{~h}$ did produce some modifications in the aspect of the crack, decorated with relatively thick matter deposits at intervals (figure 8a), a few bridges which fractured, keeping their adherence on the crack face (fig 8b), and tiny crystals, on the fracture surface, especially behind the crack front. But there again, the comparison of COD profiles at a given load before and after annealing did not reveal any significant difference.

In a specimen annealed during $67 \mathrm{~h}$ at $450^{\circ} \mathrm{C}$, many rod-like particles were observed around the crack, as well as more numerous bridges than after the heat treatments at lower temperatures (Figure 8c, d). During compression, "en échelon" crack arrays developed from both cracks (that is: above and below the starter hole) probably behind the initial crack tips, in healed portions. Figure 9 shows a sequence at rising load: at $500 \mathrm{~N}$ (only $14 \%$ of the load applied for pre-cracking) the first series of more or less parallel, inclined micro-cracks appeared and the crack seemed to be about to bifurcate by $36^{\circ}$ and to grow along such a large branch crack (number 1 on the pictures). But at $1000 \mathrm{~N}$, a second large inclined crack appeared, approximately $40 \mu \mathrm{m}$ ahead of the bifurcation point $\left(\mathrm{n}^{\circ} 2\right)$ and at $1500 \mathrm{~N}$ a third one $\left(\mathrm{n}^{\circ} 3\right)$, in-between the two previous cracks. At $2000 \mathrm{~N}$, the first one closed and nearly disappeared and at $2500 \mathrm{~N}$, the second and third joined with the main crack. On the other side of the hole, near the other crack tip, a similar scenario occurred: an alternance of popin, growth, closure and arrest of "en échelon" cracks. At the final stage (above the load applied for pre-cracking) the main crack bifurcated, clearly leaving an unbroken healed portion ahead (even 
though, a series of faint inclined lines suggest that more "en échelon" cracks might have appeared if bifurcation did not occur).

On the fracture surface, scaled areas evoking re-fracturing after healing were observed, both near side surfaces and inside. Rows of droplets radiating from platinoïds, as well as crystallisations around these particles suggest an intensive local chemical activity.

\section{III.3.c. specimens annealed in air, under compression}

A pre-cracked DCDC specimen was annealed during 250 minutes (same temperature and stress cycles as that applied for self welding of polished plates) at $450^{\circ} \mathrm{C}$ in air with $10 \mathrm{MPa}$ compression normal to the crack face. This treatment was not sufficient to heal the crack, which, even though bridged in some portions, remained opened in others. Once opened and immediately observed with an optical microscope, without touching the fracture surface with bare hands, this specimen revealed many droplets and even "pools" of water trapped in-between the crack face (Figure 10a-b). These drops were present only inside a 1 to $1,5 \mathrm{~mm}$-wide band, behind the crack front. The white deposits that can be observed on Fig. 10b seemed to follow the rim of evaporated pools. Relatively wide areas with coloured crystalline deposits detached from one of the two crack surfaces -as suggested by their complementary contours on opposite fracture surfaces- were also observed near the side surfaces (Fig. 10c-d).

A second DCDC specimen was reloaded in the ESEM after annealing during 250 minutes at $450^{\circ} \mathrm{C}$ in air with a $20 \mathrm{MPa}$ compression. Up to $1000 \mathrm{~N}$ ( $28 \%$ of the load used for pre-cracking), a large part of the crack, near the starter hole remained stuck and even invisible (Fig. 11a) and only the part closer to the tips was discernable and opened a little. Above $1800 \mathrm{~N}$, the crack became visible over its entire length (fig. 11b, c) and finally, bifurcation occurred from a few tens of microns behind both tips, as suggested by the faint traces ahead of the bifurcation points, on figure $11 \mathrm{~d}$ and e. Here again, water droplets were observed on the fracture surface, as well as large dendritic deposits, stradling the crack front (Figure 11f). The Raman spectra of these deposits were similar to those collected for the dendritic phase after vacuum annealing.

\section{III.3.d. specimens left 15 days in a lixiviate at $90^{\circ} \mathrm{C}$}

Figure 12a shows the aspect of the crack in one of the DCDC specimens left during 15 days in a solution saturated in $\mathrm{Na}, \mathrm{B}$ and $\mathrm{Si}$ at $90^{\circ} \mathrm{C}$ when it was brought back into the ESEM for compression. In the unloaded state, the crack appeared completely covered with matter and enclosed between two rows of 300 to $500 \mathrm{~nm}$-large particles. Under a $500 \mathrm{~N}$ load, the covering layer began to develop multiple cracks with a more or less regular spacing and an angle of 18 to $22^{\circ}$ with respect to the main crack (Fig 12b). As loading increased, these cracks opened and their spacing decreased (Fig. 12d), but at 2000N, the crack was still bridged continuously over a distance of 365 $\mu \mathrm{m}$ from its tip (Fig. 12c). At higher loads, the crack finally got devoid of bridges and resumed propagation from the former crack tip.

The bridging layer was quite efficient in restraining crack opening, as can be seen on figure 13a which shows the COD profiles measured under various loads in an other specimen after 15 days in 
water at $90^{\circ} \mathrm{C}$. Under $600 \mathrm{~N}$ (which would correspond to a "nominal" stress intensity factor $\mathrm{K}_{\mathrm{I}}$ of $0.097 \mathrm{MPa} \sqrt{\mathrm{m}}$ if no bridges were present) the crack was opened only over $252 \mu \mathrm{m}$ ( $8 \%$ of its length). Under $1200 \mathrm{~N}$ (nominal $\mathrm{K}_{\mathrm{I}}=0.19 \mathrm{MPa} \sqrt{\mathrm{m}}$ ) it was opened over $675 \mu \mathrm{m}(22 \%$ of its length), while the opened length reached $2665 \mu \mathrm{m}$ (86\% of the crack length), under $1800 \mathrm{~N}$ (nominal $\mathrm{K}_{\mathrm{I}}=$ $0.29 \mathrm{MPa} \sqrt{\mathrm{m}})$.

Many scaled areas, evoking healing and re-fracturing, were observed on the fracture surface, especially -but not only- near side surfaces. Needle-like particles were also present.

\section{III.3.d. specimen left 11 days in a lixiviate at $70^{\circ} \mathrm{C}$ under $5 \mathrm{MPa}$ compression}

Figure $13 \mathrm{~b}$ shows the COD profiles measured while reloading a DCDC specimen left 11 days in water under $5 \mathrm{MPa}$ compression normal to the crack face. For increasing loads corresponding respectively to nominal $\mathrm{K}_{\mathrm{I}}$ values of $0.14,0.28,0.4,0.52$ and $0.75 \mathrm{MPa} \sqrt{\mathrm{m}}$, the open fraction of the crack length was $13,38,66,73$ and $80 \%$. The crack finally resumed propagation at $4500 \mathrm{~N}$ (nominal $\mathrm{K}_{\mathrm{I}}=1.06 \mathrm{MPa} \sqrt{\mathrm{m}}$ ) which was $22 \%$ higher than the load applied for precracking.

Figure 13c compares the evolution with $\mathrm{K}_{\mathrm{I}}$ of the open fraction of the crack length after natural or mechanically-assisted healing in water. Even though the temperature was lower $\left(70^{\circ} \mathrm{C}\right.$ instead of $90^{\circ} \mathrm{C}$ ) and the duration of the treatment (11 days instead of 15) was shorter for the latter, the efficiency was improved, since the opening of the crack was restrained up to higher values of $\mathrm{K}_{\mathrm{I}}$.

\section{Numerical analysis of the results on DCDC specimens}

\section{IV.A. principle of the analysis}

A finite element model representing half a DCDC specimen was prepared with the Cast $3 \mathrm{M}$ code, using four-node quadrilateral elements, with a refined mesh around the crack tip and $3 \mu \mathrm{m}$ wide elements along the crack face. This degree of refinement was adopted after a preliminary convergence study. The loads applied during in situ experiments were simulated by a uniform pressure on the top end of the model, with symmetry boundary conditions enforced on the bottom end (fig. 14a). The COD profile along the crack face, as well as the mode I stress intensity factor were computed -the latter using the G-theta method- for plane stress, assuming either that 1) the crack face is completely free to open (Fig. 14b) or 2) that the matter which constitutes the bridges exerts locally a restraining tension stress, $\sigma_{n}$, proportional to the local crack opening displacement (COD) (Fig. 14c, d). More specifically, a normal stiffness $\mathrm{k}_{\mathrm{N}}$ is specified in $\mathrm{Nm}^{-3}$, so that:

$$
\sigma_{N}=k_{N} \cdot C O D
$$

The tensile stress on such bridging elements can be computed, so that indications on their fracture strength can be obtained from the load for which they are observed to break and from their position along the crack.

The tensile strain $\varepsilon_{\mathrm{N}}$ on an elastic bridging element of thickness $\mathrm{t}_{\mathrm{b}}$ and Young's modulus $\mathrm{E}_{\mathrm{b}}$ is: 


$$
\varepsilon_{N}=\frac{C O D}{t_{b}}=\frac{\sigma_{N}}{E_{b}}
$$

Combining equations (2) and (3) it comes:

$$
k_{N}=\frac{E_{b}}{t_{b}}
$$

Equation 4 yields a broad estimate of the order of magnitude of $\mathrm{k}_{\mathrm{N}}$, assuming that the bridges are made of a more or less dried and porous silica gel. Etienne et al. (2001) indicate that the altered layer at the surface of alkali borosilicate glasses is mainly constituted with a porous alkali-free network. Using instrumented micro-indentation on a nuclear glass leached during 120 days at $60^{\circ} \mathrm{C}$ and $\mathrm{pH}=2$, covered with a $5 \mu \mathrm{m}$ thick alteration layer, they measured a Young's modulus of $6 \mathrm{GPa}$ for this layer, and estimated its porosity as 0.56 to 0.71 from a micromechanical model . As the indentation load increased and densification occurred, the modulus rose to $18 \mathrm{GPa}$, still much lower than that of bulk glass, which was $73 \mathrm{GPa}$. For a synthetic silica gel prepared by a sol-gel method, with a porosity around 73\%, Adachi and Sakka (1990) measured a Young's modulus of 0.95Gpa for the as-prepared dry gel and $1.11 \mathrm{GPa}$ after annealing at $500^{\circ} \mathrm{C}$. If the thickness of bridging layer is assumed to range from 1 to $100 \mathrm{~nm}$, this yields a range of $5.10^{13}$ to $5.10^{15} \mathrm{Nm}^{-3}$ for $\mathrm{k}_{\mathrm{N}}$.

Three tests were simulated: the test on the DCDC specimen that was annealed at $400^{\circ} \mathrm{C}$ during $240 \mathrm{~h}$ in vacuum, that on the specimen left during 15 days in water at $90^{\circ} \mathrm{C}$ and that on the specimen left during 11 days in water at $70^{\circ} \mathrm{C}$ with a $5 \mathrm{MPa}$ normal compression. In all cases, only the main continuous bridge observed immediately behind the crack tip over a distance which decreased as the applied load rose was simulated, not the 2 to 10 micron-wide bridges that can be observed here and there beyond the main bridged portion. The length of the latter is indicated on the obtained plots.

\section{IV.b. Results of the analysis}

Under a $600 \mathrm{~N}$ load, the crack was observed to be bridged over $649 \mu \mathrm{m}$ in the vacuum-annealed specimen. Figure $14 \mathrm{~b}$ to $\mathrm{d}$ show the deformed meshes and fig. 15a the corresponding crack opening displacement profiles computed with this bridged length for various values of the bridge stiffness $\mathrm{k}_{\mathrm{N}}$. A comparison with the measured COD profiles suggests that $\mathrm{k}_{\mathrm{N}}=1.10^{15} \mathrm{Nm}^{-3}$ is the most suitable yalue, which also yields a reasonable agreement between the COD profiles computed under $1200 \mathrm{~N}$ (with an observed bridge length reduced to $314 \mu \mathrm{m}$, Fig. 15b) or under $1800 \mathrm{~N}$ (bridge length reduced to $129 \mu \mathrm{m}$, Fig. 15c) and the corresponding experimental data. Note that the near-tip displacements do not exhibit the classical $\mathrm{r}^{0.5}$ dependence when bridging is present, unless the bridge stiffness is so high as to prevent completely crack opening. That is why no stress intensity factor is reported here and why the term "nominal" $\mathrm{K}_{\mathrm{I}}$ is used above, when referring to partially healed cracks.

Figure $15 \mathrm{~d}$ shows the tensile stress profile along the crack face, depending on the bridge stiffness, under a $600 \mathrm{~N}$ load. As expected, the higher the bridge stiffness, the higher the tensile stress. Note however that stresses are computed at Gauss points lying somewhat inside the bulk of the glass, not exactly on the crack face (but quite near, thanks to the refined mesh) and that for the first and last 
nodes of the bridged part, the interpolated stress takes into account the stresses in the next and previous crack-face element. The peak tensile stress computed at the end of the bridged part is thus a bit underestimated, since this stress drops to zero in the next -unconstrained- element. The order of magnitude, about $21 \mathrm{MPa}$ for $\mathrm{k}_{\mathrm{N}}=1.10^{15} \mathrm{Nm}^{-3}$, is however believed to be reliable.

For the bridge lengths mentioned above, the peak computed tensile stress was $27 \mathrm{MPa}$ at $1200 \mathrm{~N}$ and $39 \mathrm{MPa}$ at $1800 \mathrm{~N}$. If the peak tensile stress is considered as the tensile strenght of the bridging material, the bridge should shrink as the load rises, so that the peak tensile stress rmains equal to this value. The measurement of this length for various loads would provide a mean to adjust the stiffness, so that the peak tensile stress remains constant. This process was been tried without success. The reasons are probably that 1) the thickness of the bridging layer and thus its stiffness (see equation 3) is not uniform along the crack face and 2) the tensile strength of the bridging layer is probably not single-valued, even though the material does not seem to be brittle, but rather distributed. Considering that, the range of computed peak stresses does not seem inconsistent. It lies below the range of fracture strength measured in biaxial tension in the bulk glass: 41 to $85 \mathrm{MPa}$ (Dubé et al. 2010).

Figure 15e shows that for a bridged crack, a small compressive stress appeared ahead of the crack tip to equilibrate the tensile stress along the bridged part. This partly explains why crack repropagation occurred by re-initiation of a branch crack from behind the tip, in an area under tension rather than by resumption of coplanar crack growth in an area under compression.

Figure 13 shows the crack opening displacement profiles computed with $\mathrm{k}_{\mathrm{N}}=1.10^{15} \mathrm{Nm}^{-3}$ for the specimen left during 15 days in water at $90^{\circ} \mathrm{C}$ and for the specimen left during 11 days in water at $70^{\circ} \mathrm{C}$ with a $5 \mathrm{MPa}$ normal compression, taking the measured bridged lengths into account. A good agreement with the measured COD profiles can be observed.

Fig. 16 compares the tension stress profiles along the crack face computed for various loads in those two specimens. The peak values are $11 \mathrm{MPa}$ for $600 \mathrm{~N}, 21 \mathrm{MPa}$ for $1200 \mathrm{~N}$, and $20 \mathrm{MPa}$ for $1800 \mathrm{~N}$ in the former and $44 \mathrm{MPa}$ at $1700 \mathrm{~N}, 55 \mathrm{MMpa}$ at $2200 \mathrm{~N}$ and $78 \mathrm{MPa}$ at $3200 \mathrm{~N}$.

Although the healing processes are certainly quite different during high-temperature vacuum annealing and low temperature lixiviation, the stiffness $\mathrm{k}_{\mathrm{N}}$ of the interface elements which allows finite element simulations to fit best the measured opening displacements of partially healed cracks happened to be the same. This does not necessary imply that the Young's modulus of the bridging layer is the same, since according to equation $4, \mathrm{k}_{\mathrm{N}}$ also depends on the thickness of this layer, which is not known and might be different. The tensile strength of this material seems to be somewhat smaller for natural healing in water at $90^{\circ} \mathrm{C}$, but substantially increased when a compressive stress was applied during the treatment in water..

\section{Discussion}

\section{V.1. Thermally-induced and mechanically assisted welding of glass plates.}

The fact that a complete disappearance of the interface between annealed glass plates was obtained at $450^{\circ} \mathrm{C}$ under $20 \mathrm{MPa}$ compression suggests that the decrease in the quality of bonding observed 
from the center to the side surfaces at $425^{\circ} \mathrm{C}$ under the same compression (Fig. 2a) was neither due to a non-uniformity of the applied stress nor to some curvature of the plates, all cut from the same parallel-sided glass disk. It might thus be related to a gradient in the amount of water trapped at the interface. As compression is applied and viscous deformation of the glass occurs, water is squeezed and probably flows away from the center, towards the free surfaces, along the interface. Imperfect bonding near side surfaces at $425^{\circ} \mathrm{C}$ might thus be related with the presence of residual moisture there, unlike in the central area, while a higher temperature probably allows faster elimination of moisture.

A polished glass surface is, however, not equivalent to a naturally-formed fracture surface, neither in terms of electrical state -since a fracture surface is charged - nor in terms of chemical state -since a fracture surface has got many broken bonds and is thus very chemically active-nor even in terms of roughness or degree of hydration, the latter with a paramount influence on healing, as shown by Girard et al. (2011). Moreover, the compression applied during annealing cannot be as uniform on a relatively rough crack face as on polished plate. So, even though there are striking similarities in the aspect of an imperfectly bonded interface (fig. 2e) and that of a partially healed crack (fig. 4c-d, $6 \mathrm{~b}$ ), the results obtained in welding experiments on polished plates cannot be used without care to analyze crack healing.

\section{V.2. Crack healing in DCDC specimens}

\section{V.2.a. Influence of temperature on thermally-induced crack healing}

For the DCDC specimens annealed in secondary vacuum, crack tip regression (like in fig. 6) was observed only after a heat treatment above $470^{\circ} \mathrm{C}$, while only crack bridging was observed for lower annealing temperatures. This suggests, as expected, that a higher annealing temperature promotes healing. A higher temperature should not only reduce the glass viscosity, but also accelerate all thermally-activated diffusion processes and surface chemical reactions that might be involved in healing.

\section{V.2.b. Influence of a compressive stress on crack healing}

A compressive stress normal to the crack plane clearly assists water-induced crack healing (fig. 13c and 16) and also seems to favour thermally-induced crack healing, although in the latter case only qualitative evidence (Fig. 11a-c) was obtained.

Equation 4 and the measurements of the Young's modulus of alteration layers on glass by an indentation technique from Etienne et al. (2001) gives some hints on possible explanations: an increase in bridge stiffness $\mathrm{k}_{\mathrm{N}}$ due to the combination of two effects: a compression-induced densification of the porous alteration layer, which in turn increases its modulus, $\mathrm{E}_{\mathrm{b}}$ but also a reduction of its thickness $t_{b}$. In addition, elastic strains due to the applied compression can contribute to the accommodation of the misfit between rough surfaces, as analyzed by $\mathrm{Yu}$ and Suo (1998). 
The concave meniscus end shape of the bridges observed after vacuum annealing is qualitatively consistent with the model of two-dimensional laminar capillarity-driven viscous flow between parallel plates proposed by Schwiebert and Leong (1996) and later used by Singh and Parihar (2009) to describe the second stage of crack healing. However, according to this model, annealed cracks should get filled continuously from the crack tip towards the crack mouth, which was not the case here. The discrete nature of the observed bridges might be due to crack face roughness and to some mismatch of the asperities, due to tiny relative sliding displacements. Viscous flow could then occur not only from the crack tip towards the mouth but also from discrete contact points between the crack surfaces in two opposite directions, this producing discrete bridges with a concave meniscus at both ends.

The development of "en échelon" cracks like those observed during re-loading of the specimen annealed $67 \mathrm{~h}$ at $450^{\circ} \mathrm{C}$ in air (Fig. 9) is often observed in underground rocks loaded in compression and shear and it has been investigated by Goldstein and Osipenko (2012). It is associated with the presence of antiplane (mode III) shear loading (Fig. 17a). The inclined cracks would then be the trace on the surface of twisted facets (fig. 17d). The origin of out-of-plane shearing in this experiment is puzzling. In-plane shearing (mode II) may occur in DCDC specimens when the central hole is offset horizontally from the vertical symmetry axis. For out-of-plane shearing (mode III) to occur, one has to imagine, that crack healing started from the side surfaces, so that a through crack does not exist any more and a new crack front -more or less parallel to the side surfaces- was formed (Fig. 17b-c). The presence of unbroken ligaments in-between the "en echelon" cracks would be consistent with that idea, since locally, the crack would not extend to the free surface. Additional experiments on DCDC specimens cut in a transparent glass would be useful to investigate the 3D aspects of crack healing.

The crystalline deposits with a dendritic aspect observed on the crack face are reminiscent of those observed by Roach et al. (1988) in mica, fused silica and soda-lime glass. They found that: "such layers are most readily formed in aqueous solutions but may also result from capillary condensation in air. The process is enhanced by alkali content in glass and by temperature".

\section{V.2.c. Modeling of crack bridging}

Roach et al. (1988) concluded that such layers efficiently bridge the crack, thus increasing the resistance to propagation and modeled this effect by introducing a restraining traction on the crack wall representing the fracture strength of the bridging matter. From an inverse analysis, they deduced a value of $48.2 \mathrm{MPa}$ for the strength of the bridges in soda-lime glass. However, a model in which the bridging matter exerts a restraining stress proportional to the local crack opening displacement, as in the present study, is probably more representative of the behaviour of the bridging matter than a model in which the restraining stress is considered uniform and independent of the local strech of the bridging material.

According to equation 4 , the thickness of the bridging layer, $t_{b}$, plays an important role and it is difficult to derive any accurate information on the mechanical strength of this layer if this parameter, certainly variable along the crack face is not known. AFM measurements would probably constitute a good method to determine this thickness, but with two major difficulties. First, 
the specimen would have to be cracked open and thus the bridging layer broken to allow such measurements on the two mating parts. Second, the AFM measurements performed by Watanabe et al. (1994) have shown that the roughness of freshly broken soda-lime and alkali-silica glass evolves quite fast, at room temperature, when it is exposed to humid air, with formation of up to $70 \mathrm{~nm}$-high swellings in three days. Even for specimens stored in vacuum, 10nm-high protrusions can form within a few days. The measurements should thus be performed as soon as possible after fracture.

\section{Conclusions and further work.}

Closure of indentation-induced cracks was observed during annealing of borosilicate glass disks at $400^{\circ} \mathrm{C}$ in an ESEM, but this purely visual technique was not considered very useful to evaluate the efficiency of crack healing treatments. Combined experimental and numerical protocols have thus been developed for a mechanical assessment of the efficiency of crack healing treatments. These protocols by themselves constitute a useful outcome of this work and are now being applied to selfhealing of glasses for high-temperature seals in SOFC.

DCDC specimens were pre-cracked in an ESEM and then either annealed at various temperatures $\left(350\right.$ to $490^{\circ} \mathrm{C}$ ) in secondary vacuum or in air, or left in water at 70 to $90^{\circ} \mathrm{C}$, sometimes under a compressive stress normal to the crack face. The specimens were then reloaded in the ESEM. The crack aspect and its opening displacements under a given load were compared to those measured during pre-cracking.

Cracks annealed above $400^{\circ} \mathrm{C}$ as well as those left in water at low temperature were bridged by an alteration layer over a distance from the crack tip which decreased as loading increased. The restraining effect of these bridges on crack opening was assessed via finite element simulations, using interface elements. The tensile strength of the bridging layer was estimated as $27-39 \mathrm{Mpa}$ after vacuum annealing at $400^{\circ} \mathrm{C}, 11-20 \mathrm{MPa}$ after 15 days in water at $90^{\circ} \mathrm{C}$ and $44-78 \mathrm{MPa}$ after 11 days in water at $70^{\circ} \mathrm{C}$ under $5 \mathrm{MPa}$ normal compression. Crack opening was restrained up to higher values of $\mathrm{K}_{\mathrm{I}}$ after mechanically-assisted water-induced healing.Thermally-healed cracks did not resume propagation from their former crack tip, but due to branch cracks re-initiated a few hundred microns behind it which grow avoiding the healed area. This behaviour was explained using finite element simulations.

In future experiments, efforts will be made to measure the thickness of the bridging layer, which certainly varies along the crack face and has an important influence on the efficiency of the bridges.

Additional experiments on DCDC specimens cut in a transparent glass would also be useful to investigate the $3 \mathrm{D}$ aspects of crack healing.

The present results suggest that both the long period during which nuclear waste blocks will remain hot as well as their contact with underground water after cooling are likely to heal some of the cracks that it contains, especially those submitted to a normal compression or even to a weak mode I loading below the subcritical crack growth threshold. However, the relatively smooth cracks investigated here are not fully representative of the 3D rough crack networks that form upon vitrification. Crack healing experiments on glass cylinders containing such a crack network -formed by thermal shock as described in (Mallet et al. 2013) - and then annealed or left in water under a 
hydrostatic pressure while monitoring their permeability and effective elastic properties via measurements of acoustic wave velocities (Mallet et al. 2013) would be useful. Water-induced and mechanically assisted crack healing experiments should be performed over much longer periods than the preliminary -but promising- tests reported here.

It would also be interesting to determine how the radiation effects would influence the healing capability of nuclear glass.

\section{Acknowledgments.}

The CEA, Andra and AREVA are gratefully acknowledged for supporting this study. The contribution of Sungmin Yoon to the experiments during his master's internship is also acknowledged.

\section{References}

Adachi T, Sakka S (1990) Dependence of the elastic moduli of porous silica gel prepared by the solgel method on heat treatment. J. Mater. Sci. 25:4732-37

Barth N, George D, Ahzi S, Rémond Y et.al. (2012) Modeling and Simulation of the Cooling Process of Borosilicate Glass. J. Engng. Mater. Techn. Trans. ASME 134 n 4, 041001-041010 Bartolomew RF (1983) High-water containing glasses, Journ. Non-crystalline solids 56: 331-342 Cheeseman GL, Lawn BR (1970) Healing of cone cracks in glass. Phys. Stat. Solidi A, 3:951-958

Doquet V, Ben Ali N, Constantinescu A, Boutillon X (2013) Fracture of a borosilicate glass under triaxial tension, Mech. of Mater, 57 n 2:15-29

Downs RT (2006) The RRUFF Project: an integrated study of the chemistry, crystallography, Raman and infrared spectroscopy of minerals. Program and Abstracts of the $19^{\text {th }}$ General Meeting of the Int. Mineralogical Association in Kobe, Japan O03-13 http://rruff.info

D'Souza AS, Pantano C (2002), Hydroxylation and dehydroxylation behaviour of silica glass fracture surfaces, J. Amer. Ceramic Soc. 85 n6:1499-1504

Dubé M, Doquet V, Constantinescu A et al. (2010), Modelling of Thermal Shock-Induced Damage in a Borosilicate Glass. Mech. of Mater.42:863-872

Etienne P, Calas S, Portal S (2001) Mechanical behaviour of corroded surface layers on glass. Phys. Chem. Glasses $42 \mathrm{n}^{\circ} 4 / 5$ : 320-323

Girard R, Faivre A, Despetis F (2011), Influence of water on crack self-healing in soda-lime silicate glass, J. Amer. Ceram. Society, 94 n 8: 2402-2407

Goldstein RV, Osipenko NM (2012), Successive development of the structure of a fracture near the front of a longitudinal shear crack. Dodlaky Physics, 57 nº $281-284$

He MY, Turner MR, Evans AG (1995) Analysis of the double cleavage driller compression specimen for interface fracture energy measurements over a range of mode mixities. Acta Met. Mat, $43 n^{\circ} 9: 3453-58$ 
Hirao K, Tomozawa M (1987) Kinetics of crack tip blunting of glasses, J. Amer. Ceramic Soc. 70 $n^{\circ} 1: 43-48$

Holden MKC, Frechette VD (1989) Healing of glass in humid environments, J. Amer. Ceramic Soc. $72 \mathrm{n}^{\circ} 11: 2189-93$

Hrma P, Han WT, Cooper AR (1988) Thermal healing of cracks in glass, J. Non-crystalline solids 102: $88-94$

Kese KO, Li ZC, Bergman B (2006) Contact residual stress relaxation in soda-lime glass. Part II. Aspects relating to strength recovery. J. Amer. Ceramic Soc. 26: 1013-1022

Mallet C, Fortin J, Guegen Y. Bouyer F. (2013) Effective elastic properties of cracked solids: an experimental investigation, Int. J. fracture 182: 275-282

Méar FO, Coillot D, Podor R, Montagne L (2011) Self healing process in glassy materials. In: Self healing at the nanoscale: mechanisms and key concepts of natural and artificial systems, V. Amendola and M. Meneghetti editors, CRC press, 269-290

Michalske TA, Fuller Jr. ER (1985) Closure and repropagation of healed cracks in silicate glass, J. Amer. Ceramic Soc. 68 n¹1: 586-590

Roach DH, Lathabal S, Lawn BR (1988) Interfacial layers in brittle cracks. J. Amer. Ceram. Soc. 71 (2): $97-105$

Schwiebert MK, Leong WH (1996) Underfill flow as viscous flow between parallel plates driven by capillarity action, IEEE transactions on components, packaging and manufacturing technology, Part C, Vol. 19 n²: 133-137

Singh RN, Parihar SS (2009) Self healing behaviour of glasses for high temperature seals in solid oxide fuell cells in: Advances in solid oxide fuell cells III: ceramic and engineering science proceedings, N.P. Bansal, J. Salem, D. Zhu editors, 325-332, J. Wiley \& sons

Stavrinidis B, Holloway DG (1983) Crack healing in glass, Physics and Chemistry of glasses 24 $\mathrm{N}^{\circ} 1: 19-25$

Watanabe Y, Nakamura Y, Dickinson JT, Langford SC (1994) Changes in air-exposed fracture surfaces of silicate glasses observed by atomic force microscopy, J. Non Crystalline solids 177: 925

Widerhorn SM, Towsend PR (1970) Crack healing in glass, J. Amer. Ceramic Soc. 53 n9: 486-489

Wilson BA, Case ED (1997) In situ microscopy of crack healing in borosilicate glass. J. Mater. Science 32: 3163-3175

Wilson BA, Case ED (1999) Effect of humidity on crack healing in glass from in situ investigation using an ESEM. J. Mater. Science 34: 247-250

Xie L, Sun D, Zhou J (2013) Electrification of glass by fracture, Proc. $13^{\text {rd }}$ Int. Conf. Fracture, ICF13, Beijing June 16-21

Yu HH, Suo Z (1998) A model of wafer bonding by elastic accommodation, J. Mech. Physics Solids $46 \mathrm{n}^{\circ} 5$ : 829-844 


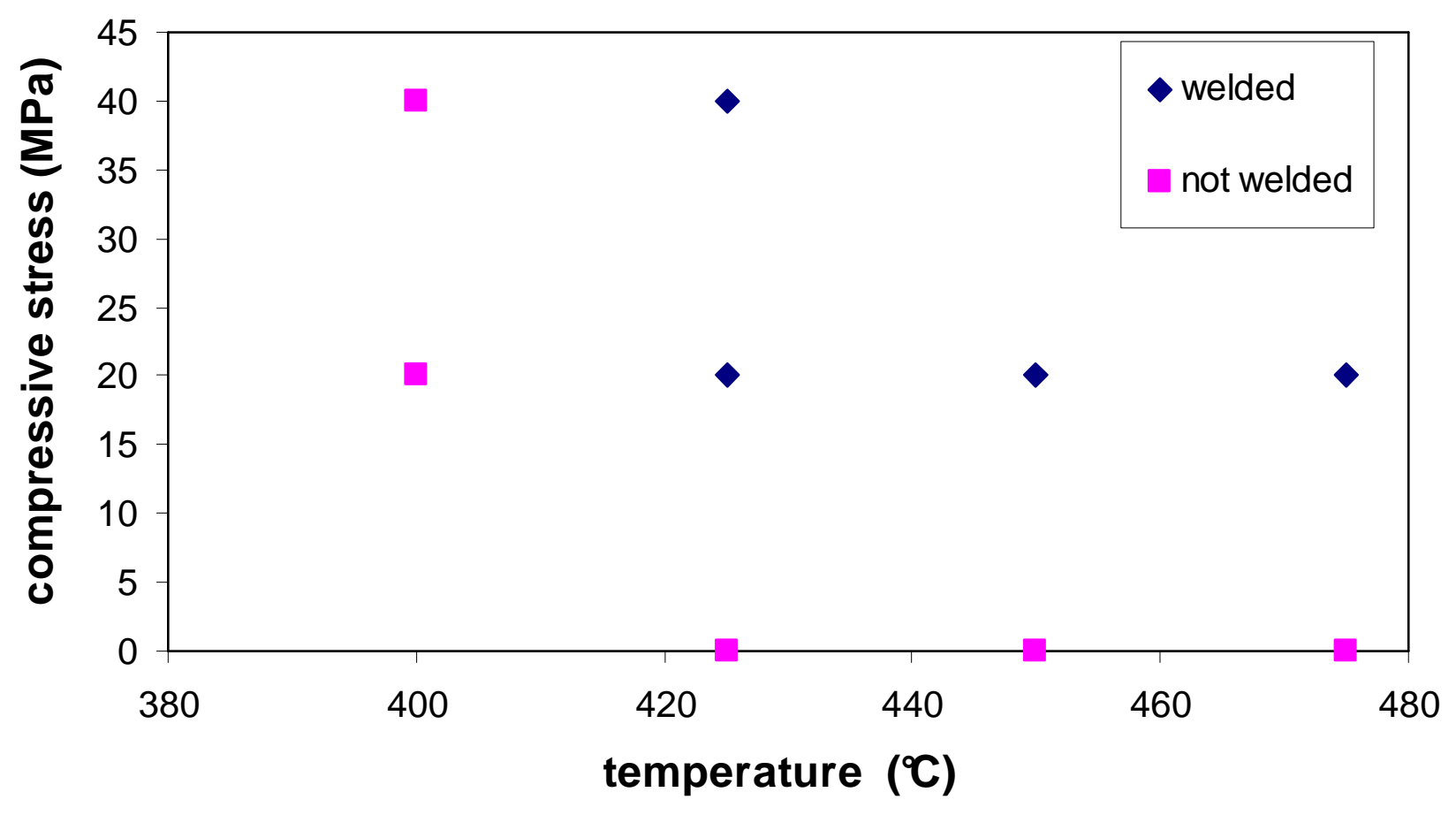

Figure 1: Conditions of plate welding experiments and qualitative results 


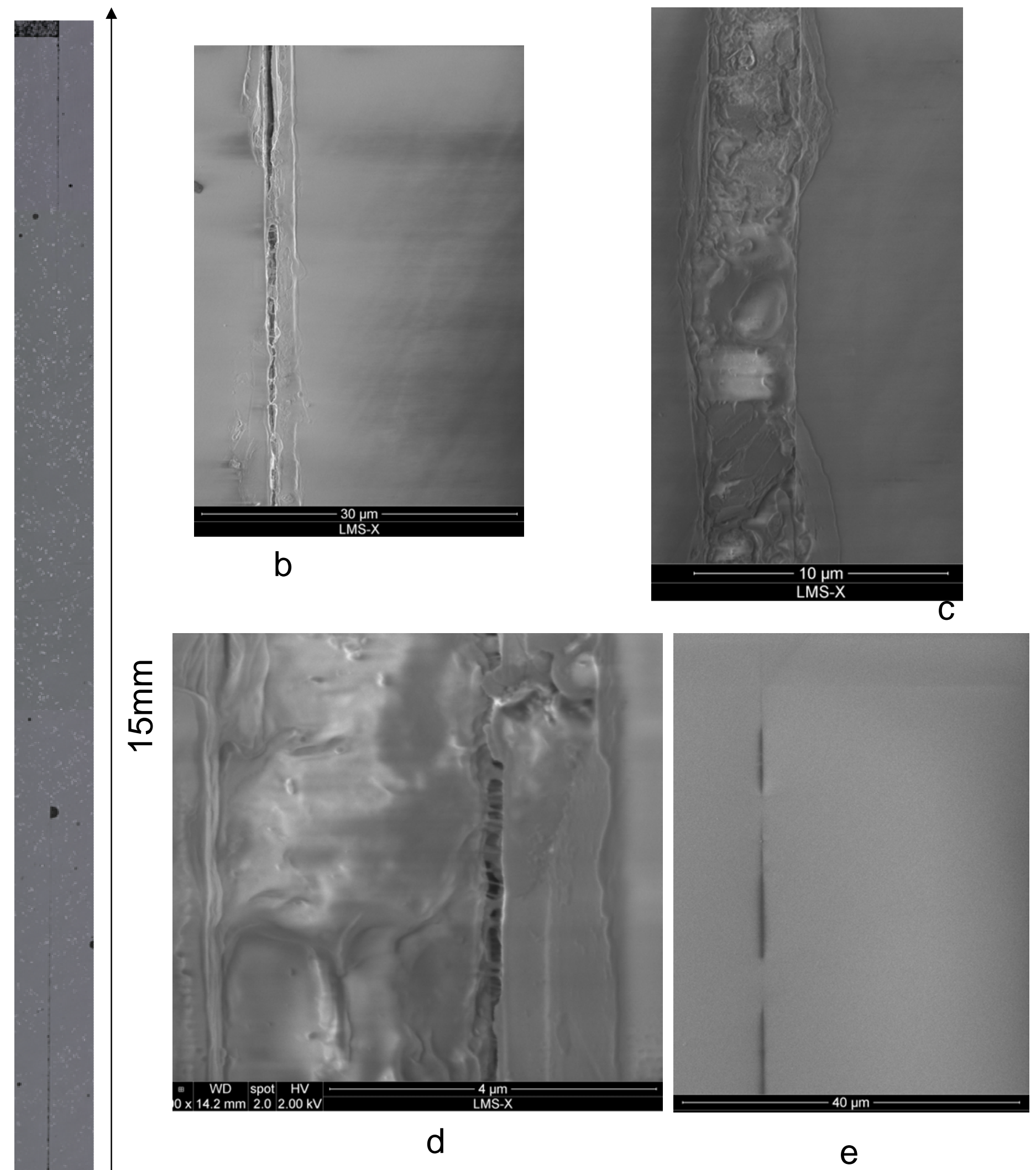

a Figure 2: SEM observation of a polished section of plates welded at $425^{\circ} \mathrm{C}$ under $20 \mathrm{MPa}:$ a) disappearance of the interface only in the centre of the plates $b$ ) to e) zoom on imperfectly-bonded parts 

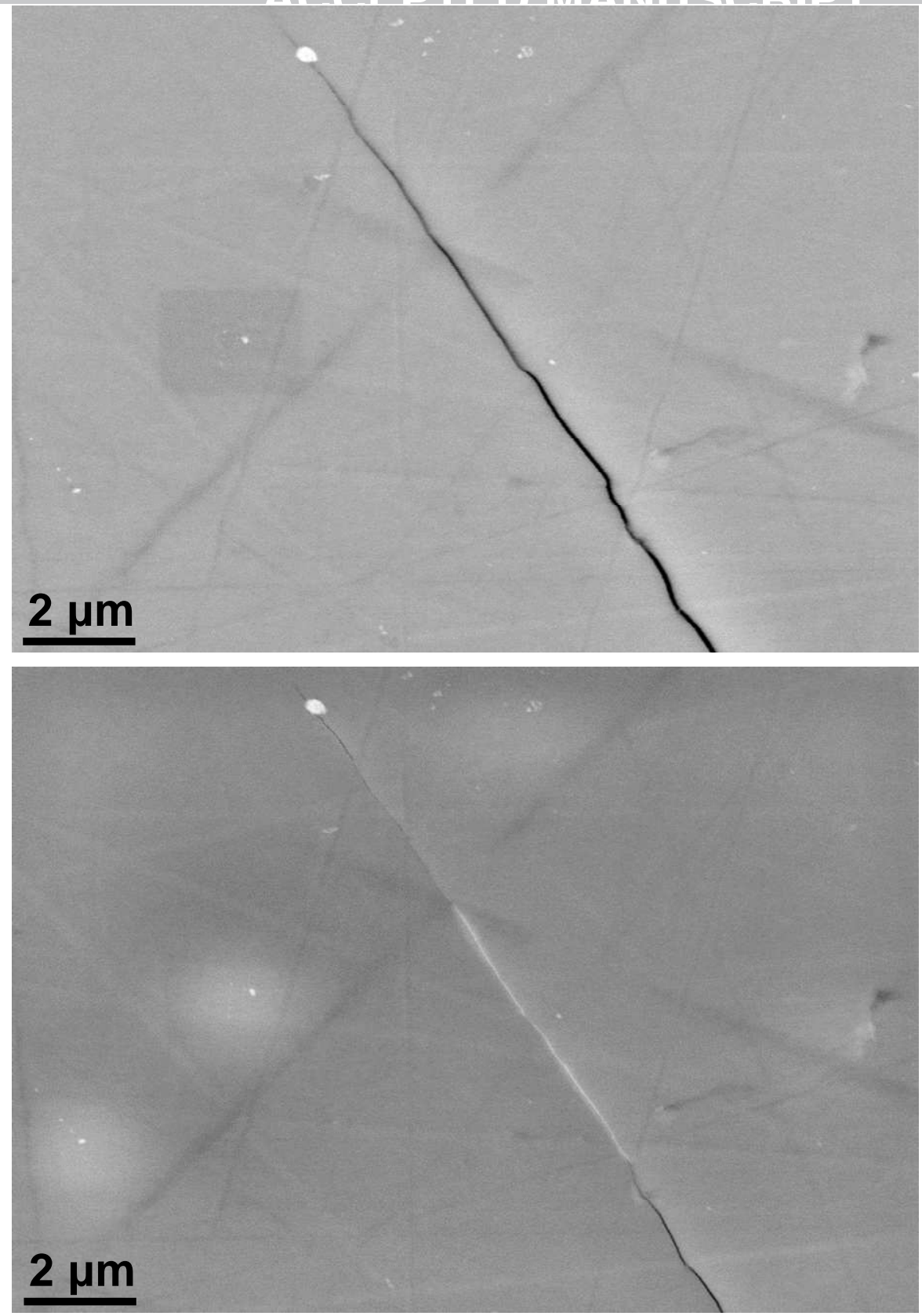

Figure 3. Closure of an indentation-induced crack during $4 \mathrm{~h} 20$ annealing at $400^{\circ} \mathrm{C}$ 


\section{$436 N$}

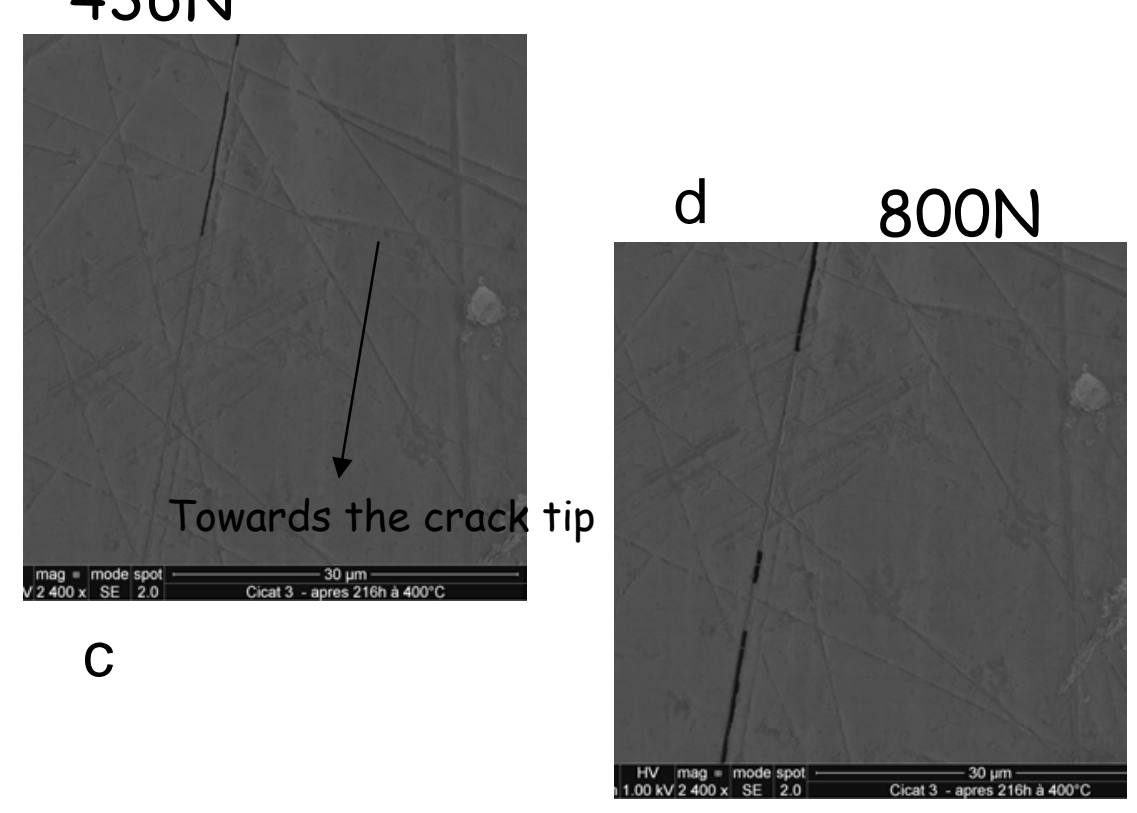

$1000 N$

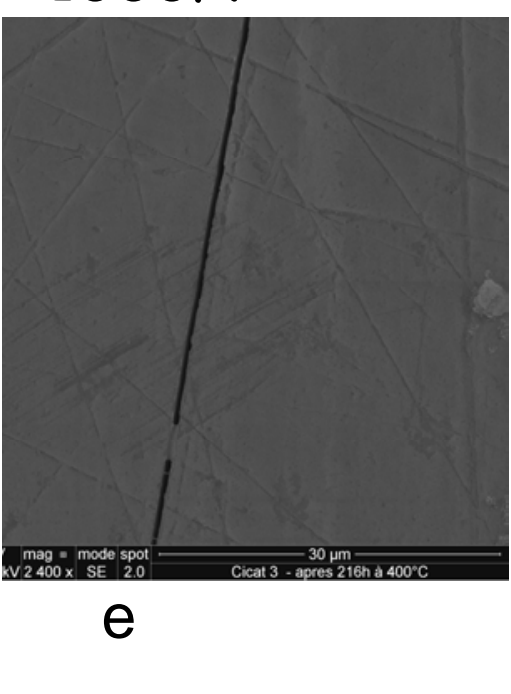

b

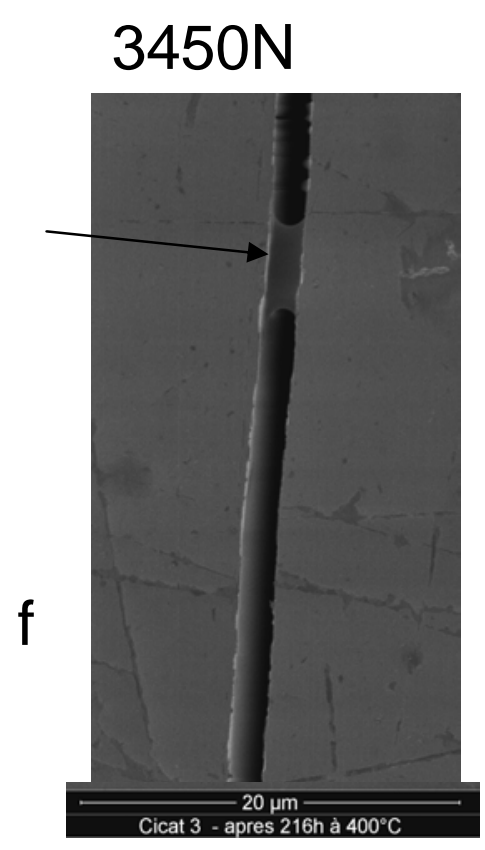

Figure 4: Bridges formed along a crack in vacuum annealed DCDC specimen a)-b) during 20 hours, c)-f) during $216 \mathrm{~h}$ 
a)

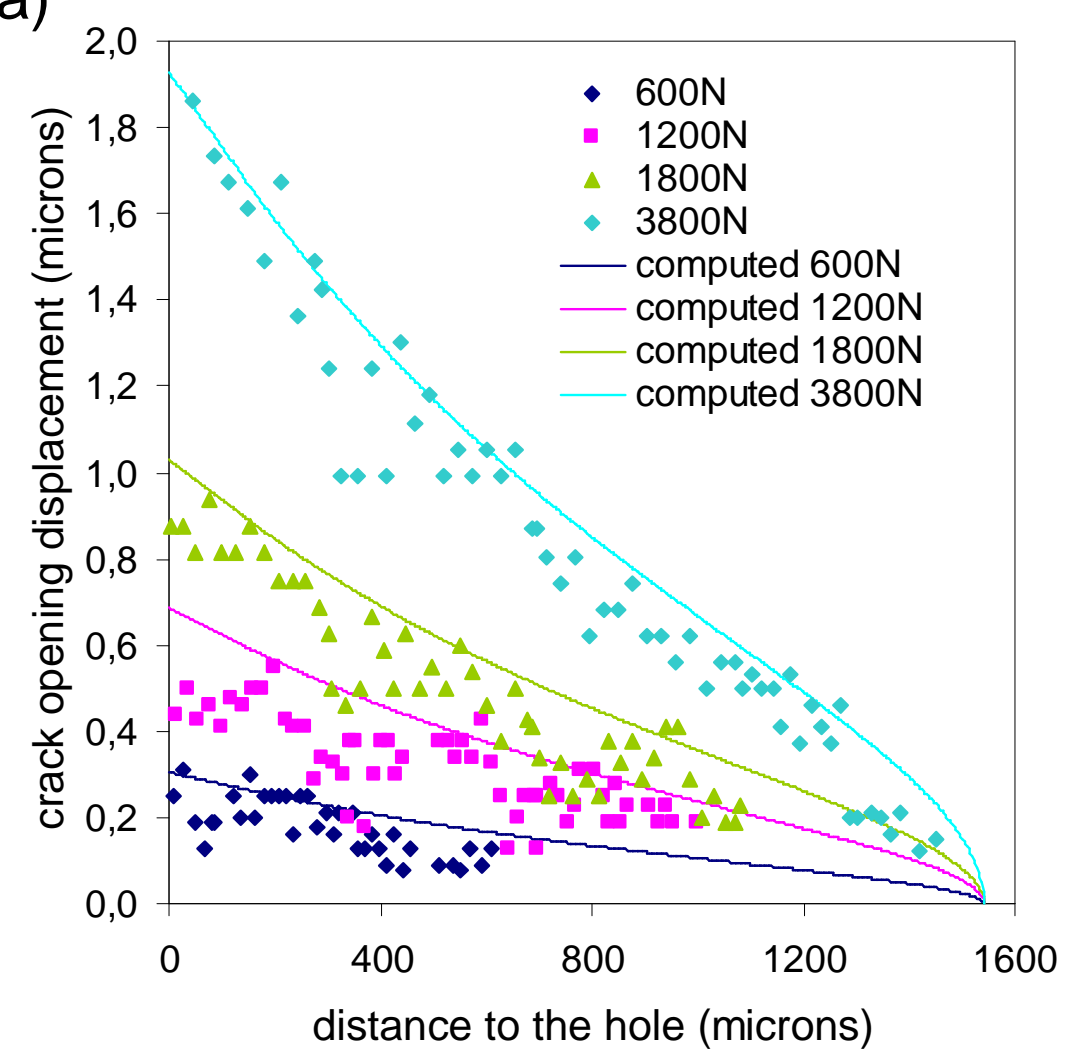

b)

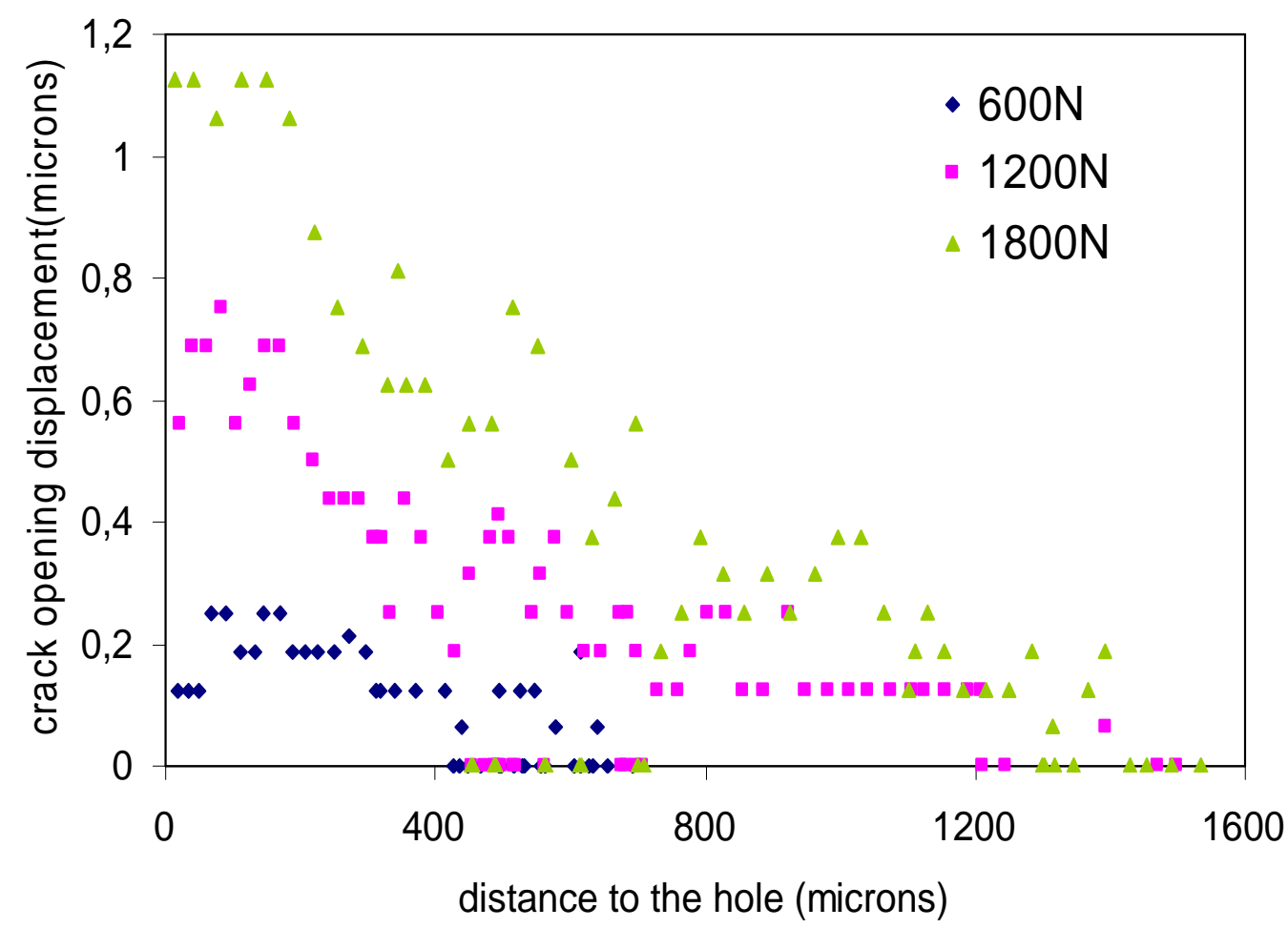

Figure 5: Measured crack opening displacement profiles in a DCDC specimen a) during precracking and b) after $240 \mathrm{~h}$ vacuum anneal at $400^{\circ} \mathrm{C}$ 
a)
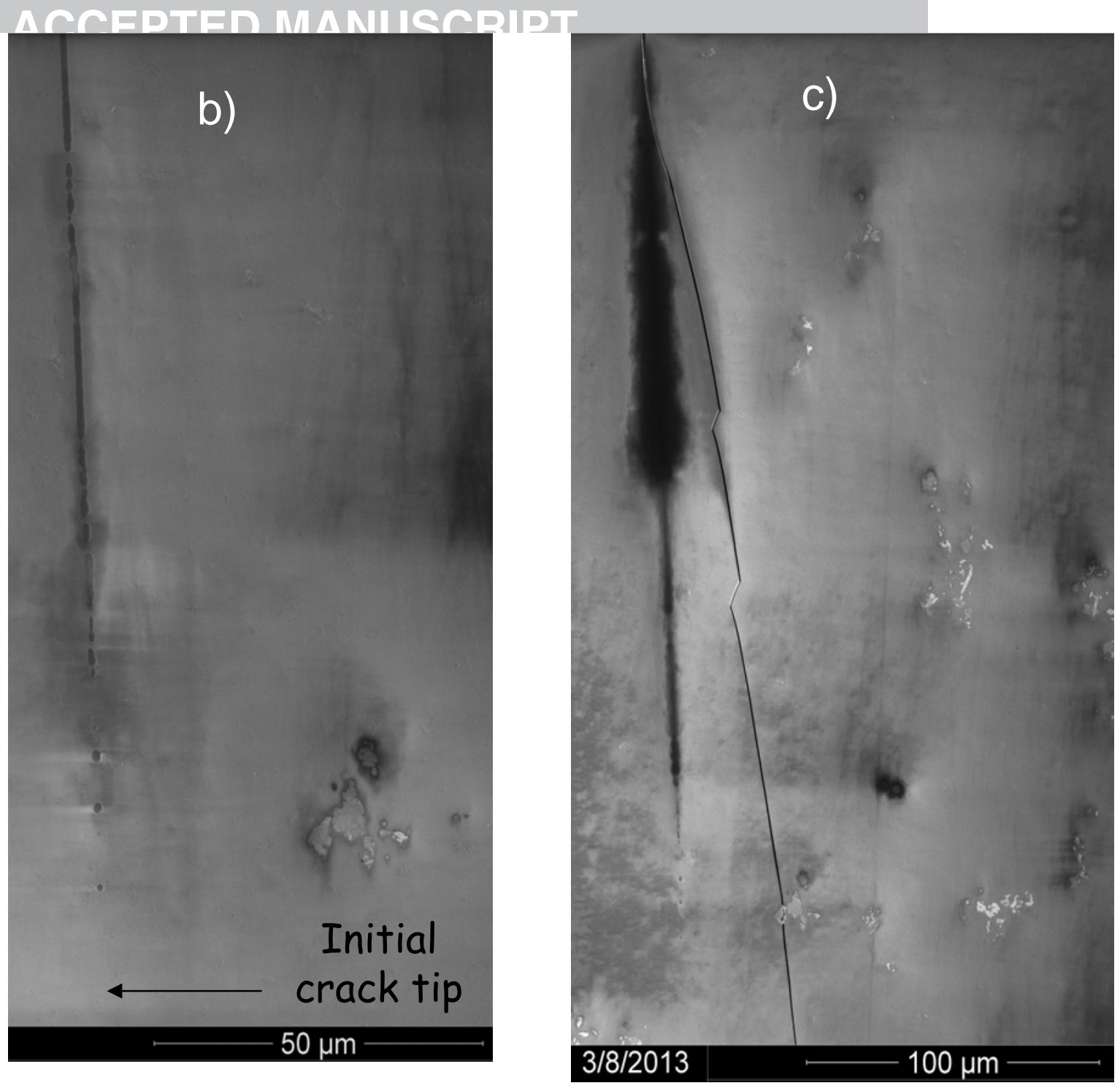

Figure 6: a) initial aspect and b) regression of the crack tip in a DCDC specimen vacuum annealed during $120 \mathrm{~h}$ at $470^{\circ} \mathrm{C}$, with a $2 \mathrm{~h} 30$ excursion to $490^{\circ} \mathrm{C}$ c) re-initiation of a branch crack at $3600 \mathrm{~N}$ compression 

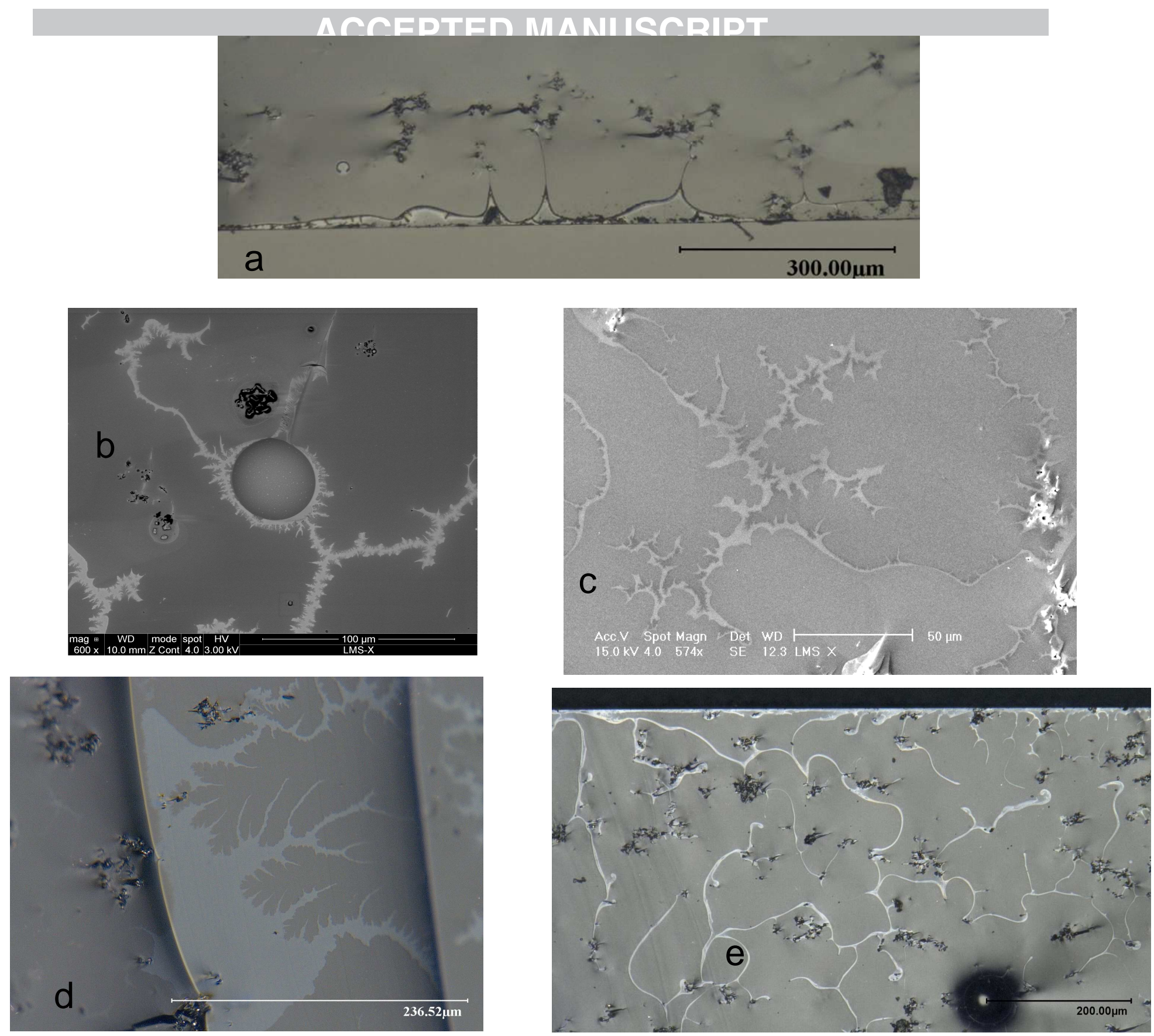

Figure 7: Features on the fracture surface of vacuum-annealed DCDC specimens a) $20 \mathrm{~h}$ at $\left.400^{\circ} \mathrm{C}, \mathrm{b}-\mathrm{c}\right) 216 \mathrm{~h}$ at $400^{\circ} \mathrm{C}$ d) $240 \mathrm{~h}$ at $400^{\circ} \mathrm{C}$ and e) 250 minutes at $490^{\circ} \mathrm{C}$ 

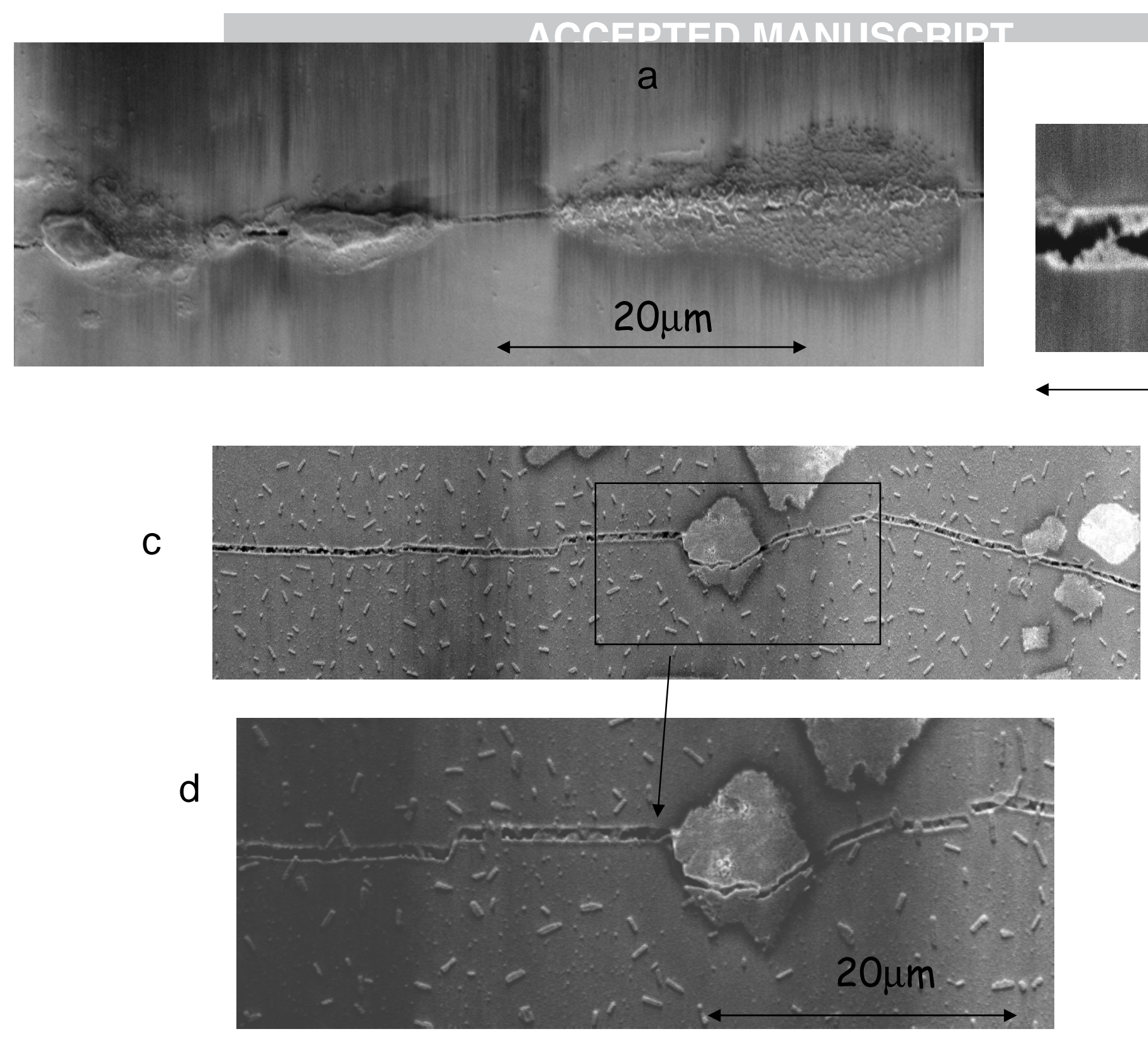

Figure 8: Aspect of cracks in DCDC specimens annealed in air a) b) during 209h at $400^{\circ} \mathrm{C}, \mathrm{c}$ ) d) during $67 \mathrm{~h}$ at $450^{\circ} \mathrm{C}$ 


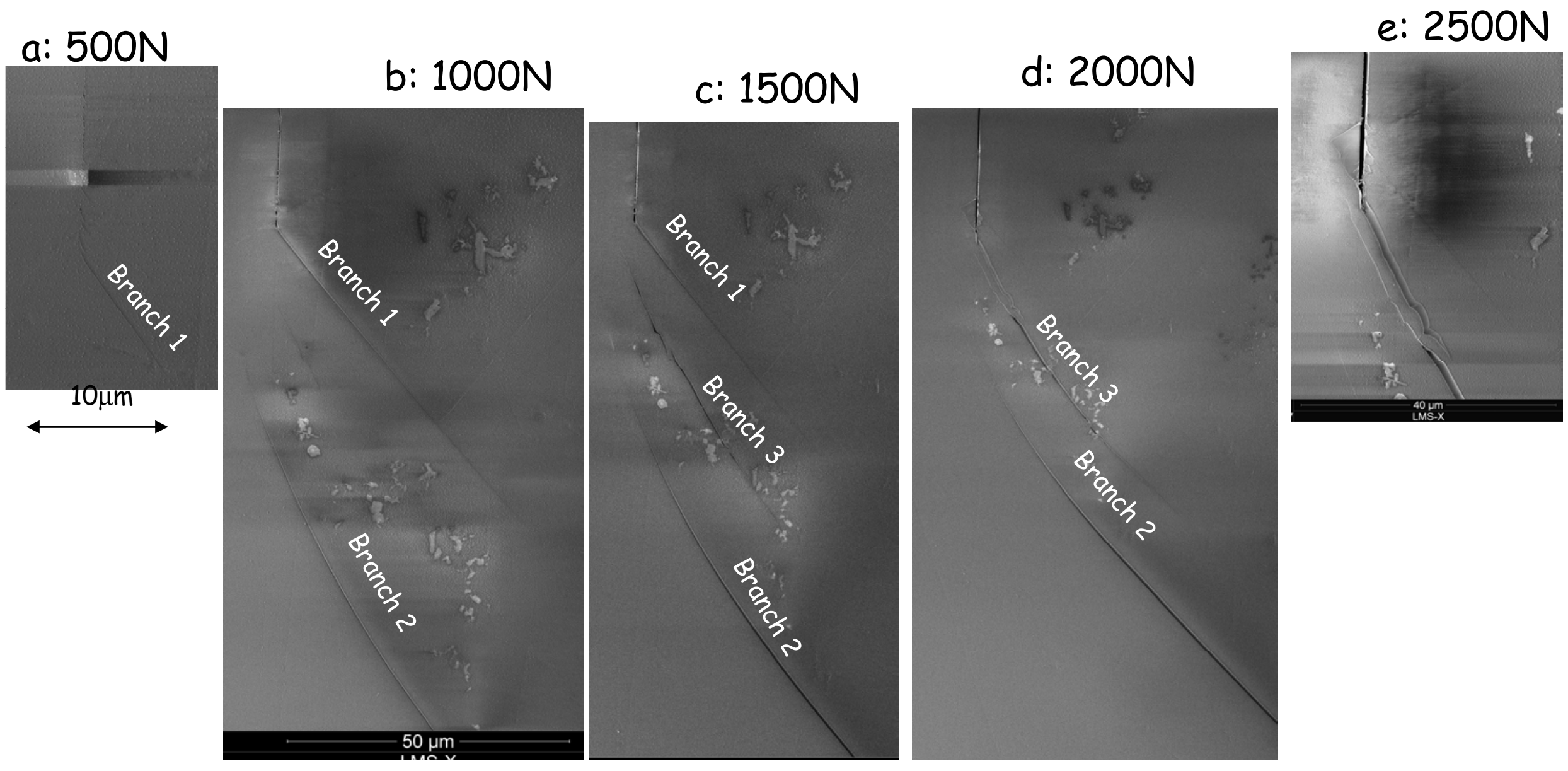

Figure 9: Re-propagation of a crack in a DCDC specimen annealed $67 \mathrm{~h}$ at $450^{\circ} \mathrm{C}$ in air 


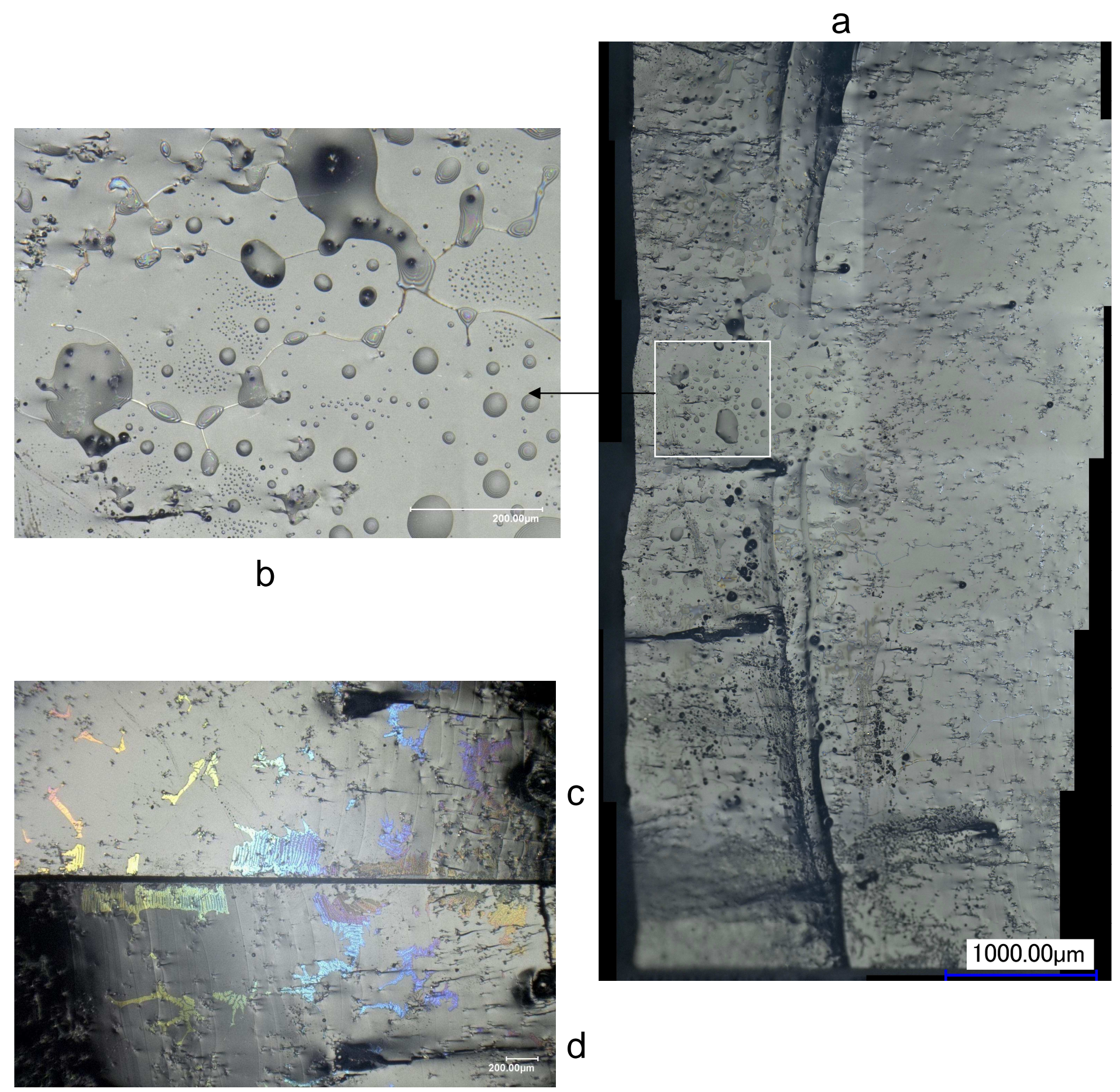

Figure 10: a-d) Drops and pools of water trapped near the front of a crack and d-e) Crystalline deposits with complementary patterns on the mating fracture surfaces of a DCDC specimen annealed 250 minutes at $450^{\circ} \mathrm{C}$ in air with $10 \mathrm{MPa}$ compression 

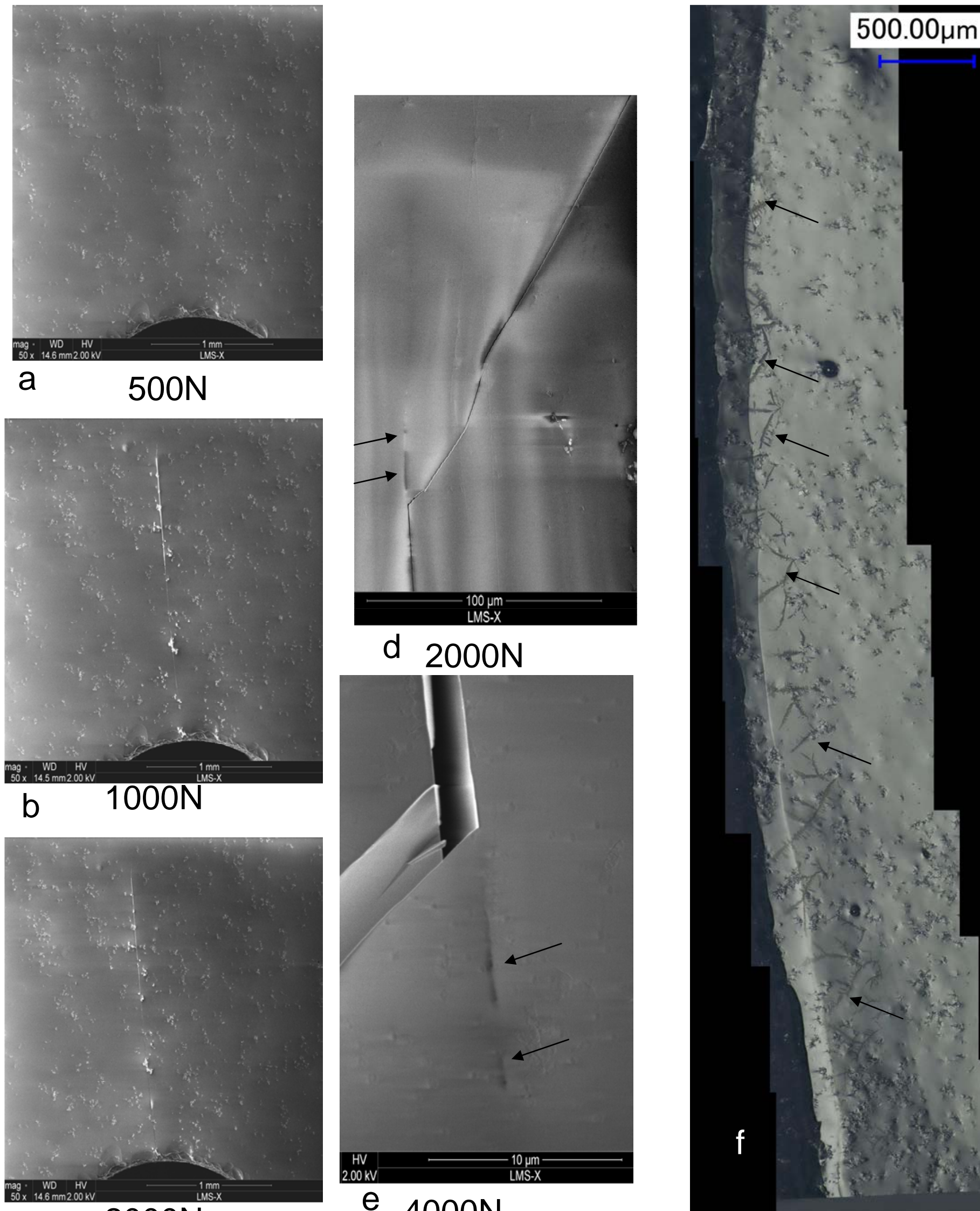

C 2000N
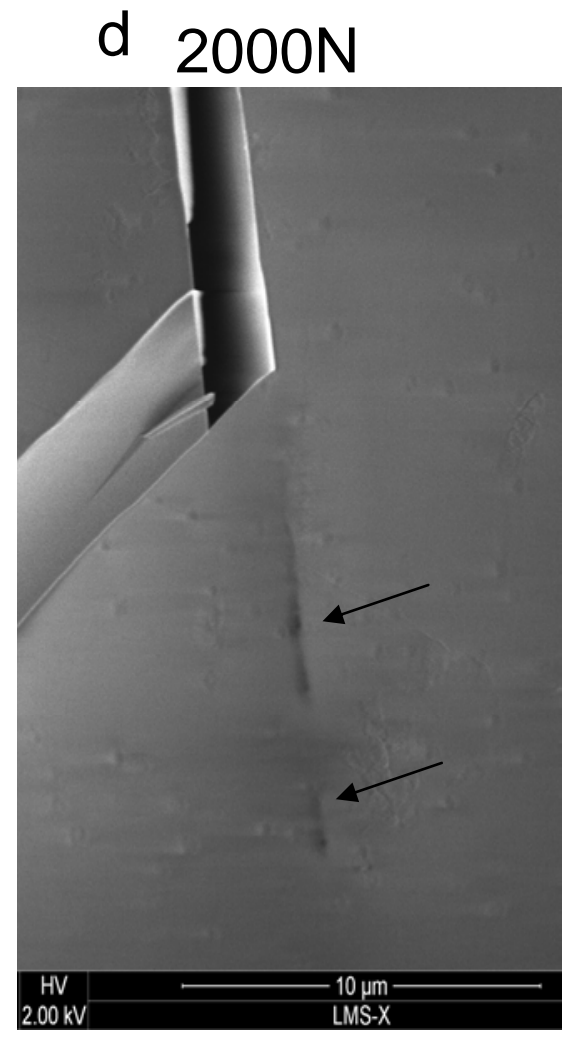

e $4000 \mathrm{~N}$

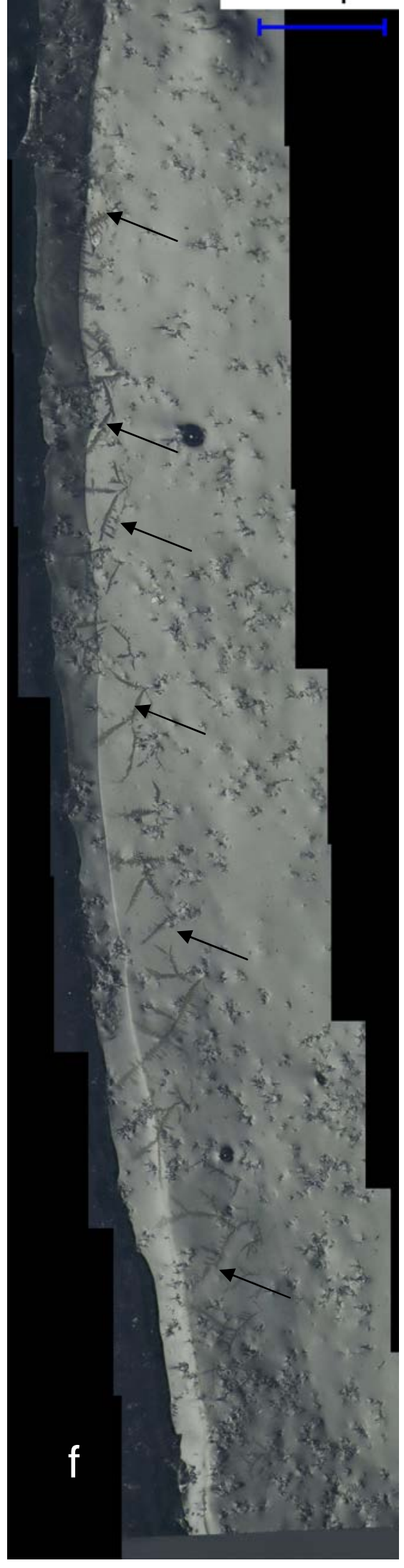

Figure 11: Re-propagation of a crack in a DCDC specimen annealed 250 minutes in air at $450^{\circ} \mathrm{C}$ under $20 \mathrm{MPa}$ compression (a to e)

f) fracture surface 

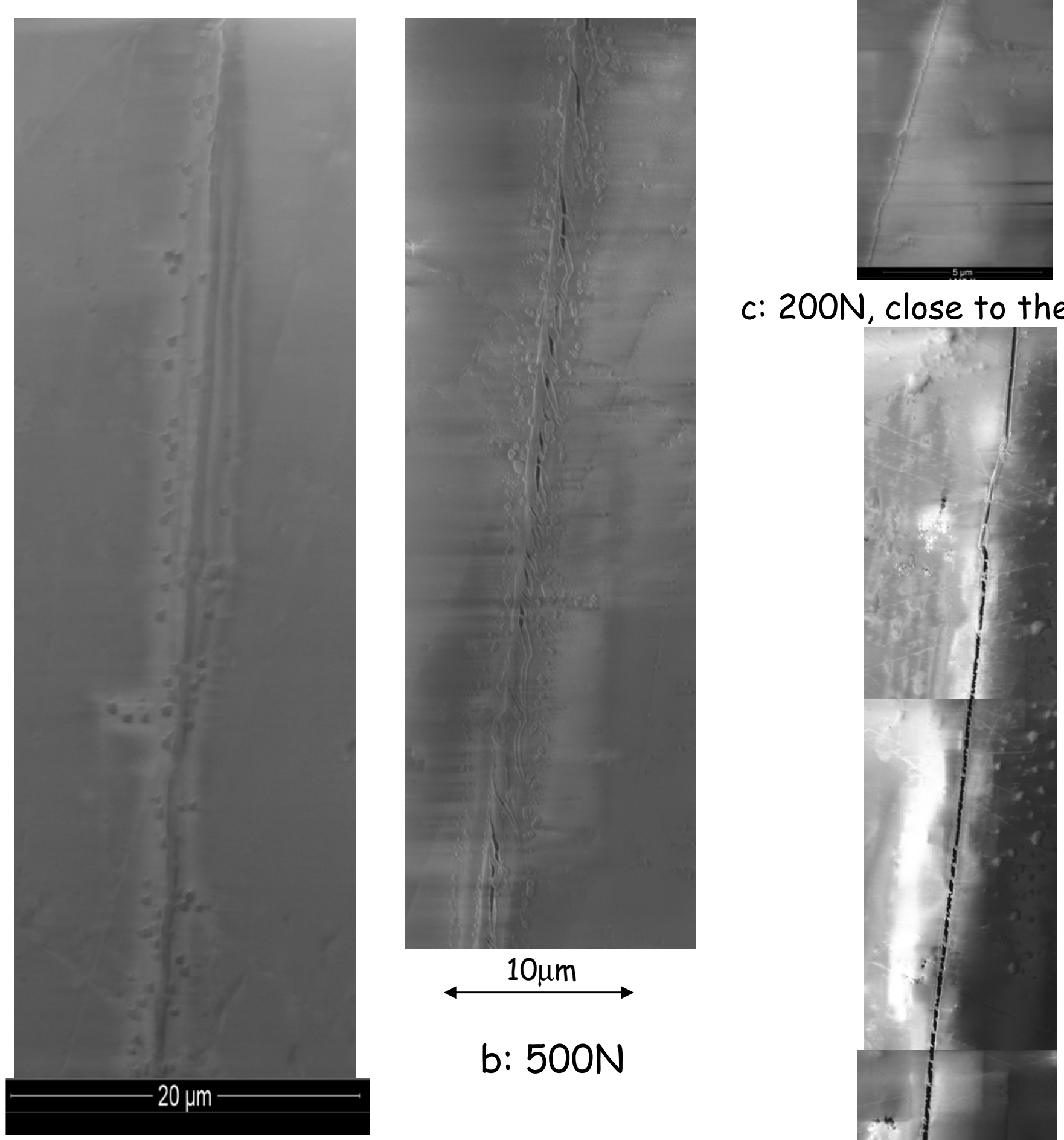

c: $200 N$, close to the tip

$a: F=0$

$10 \mu m$

b: $500 \mathrm{~N}$
Figure 12: Re-propagation of a crack in a $D C D C$ specimen after 15 days in water at $90^{\circ} \mathrm{C}$

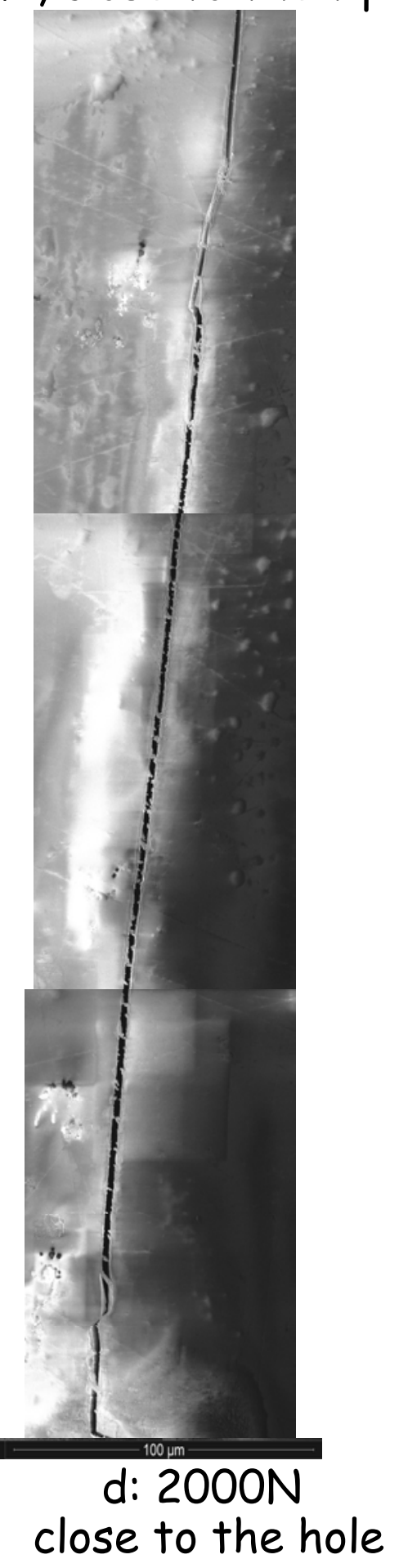




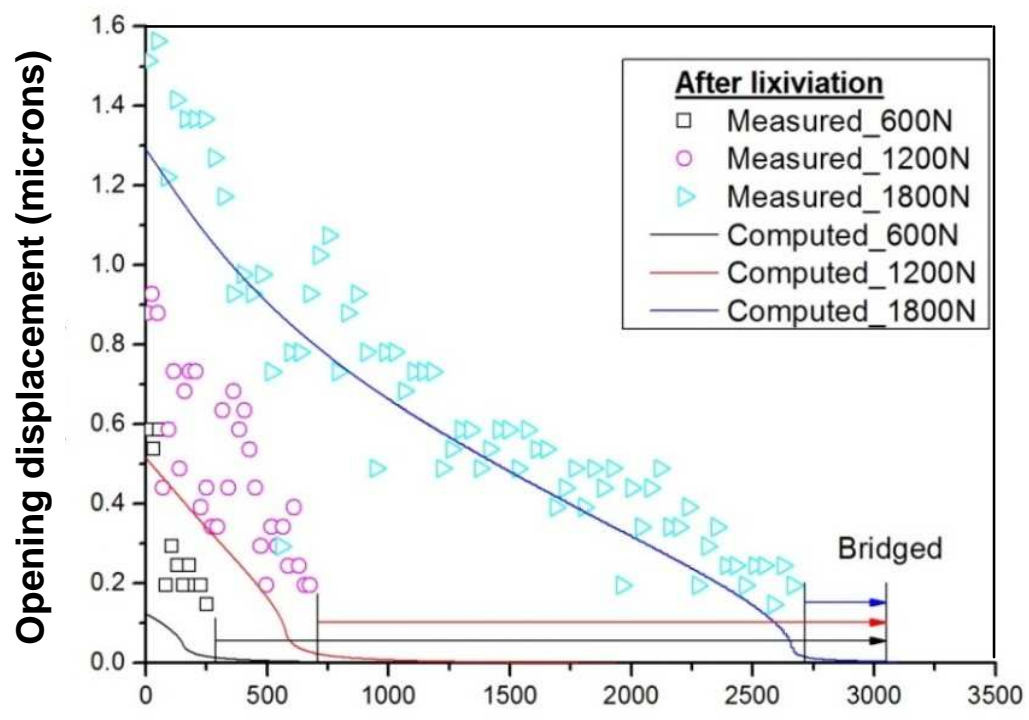

a)

\section{Distance to the hole (microns)}
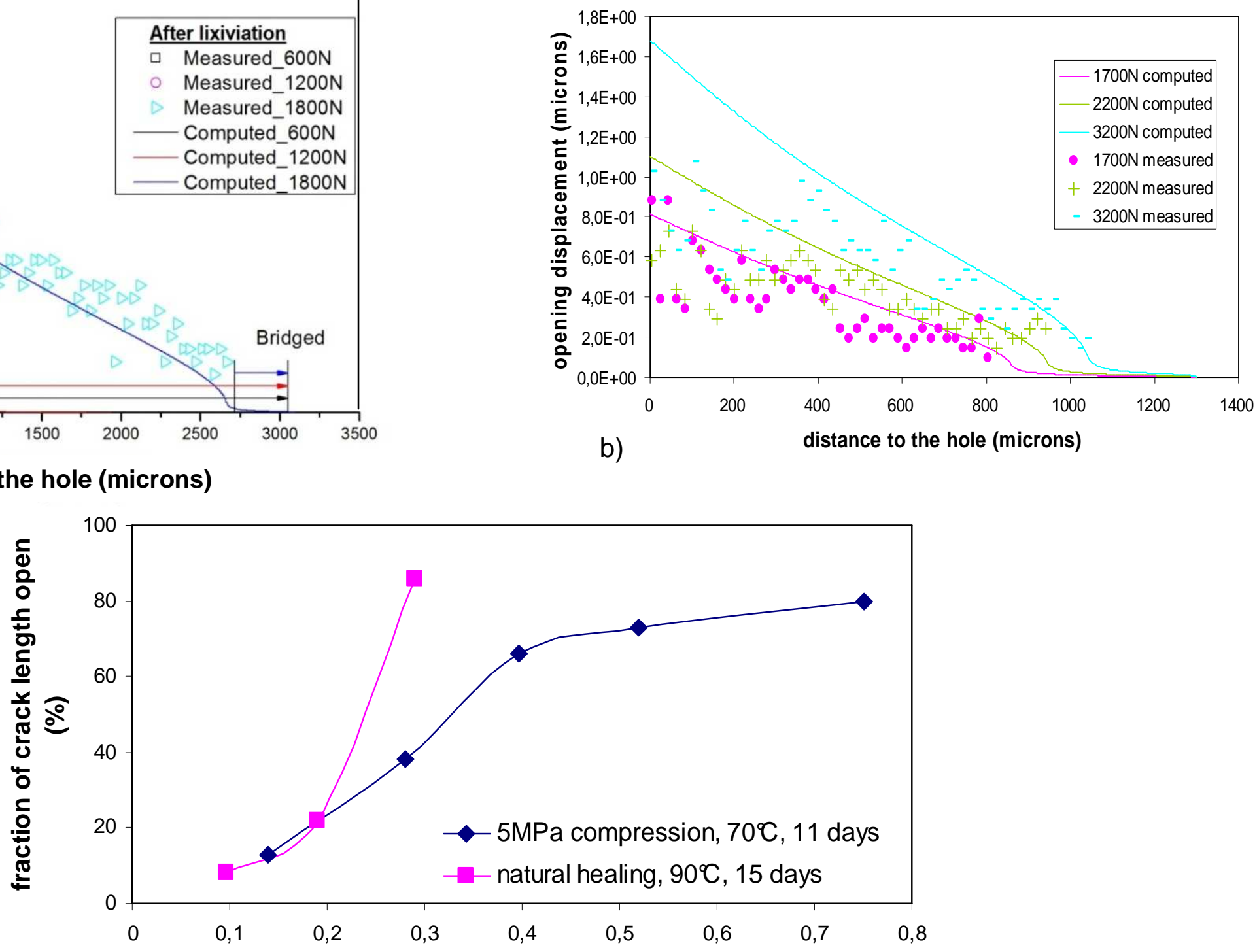

C)

\section{Nominal $\mathrm{K}_{\mathrm{l}}(\mathrm{MPa} \sqrt{ } \mathrm{m})$}

Figure 13: crack opening displacement profiles measured a) in a DCDC specimen left 15 days at $90^{\circ} \mathrm{C}$ in a lixiviate and b) in a DCDC specimen left 11 days at $70^{\circ} \mathrm{C}$ in a lixiviate under $5 \mathrm{MPa}$ compression normal to the crack face.

c) compared evolution of the open fraction of crack length 
a 0000 คे०ि

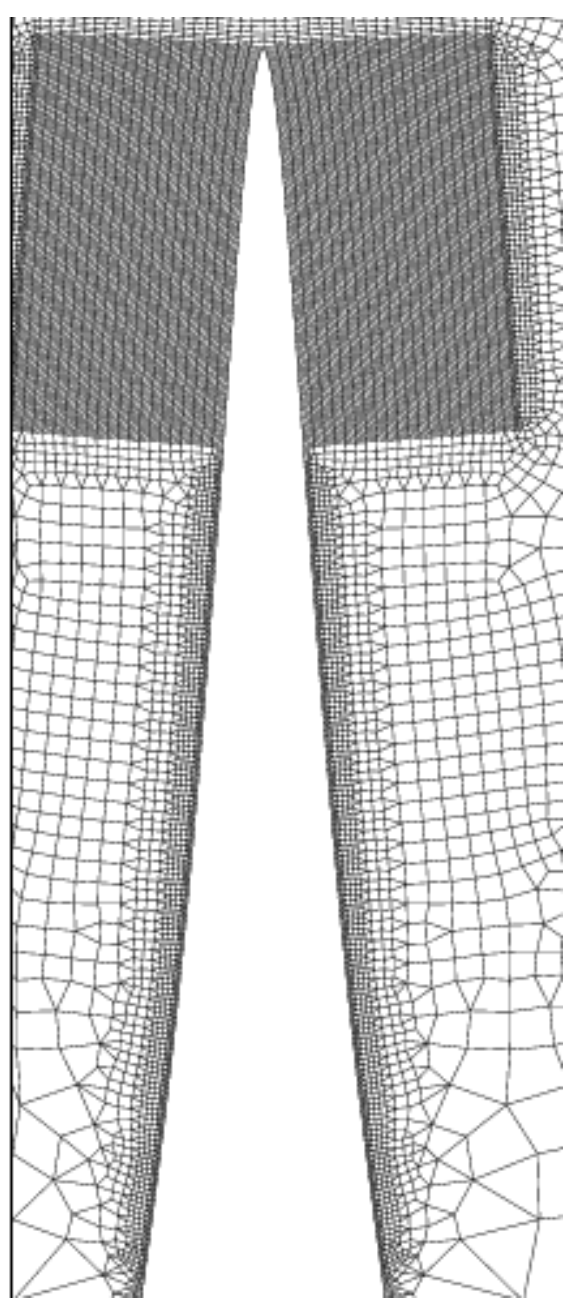

b

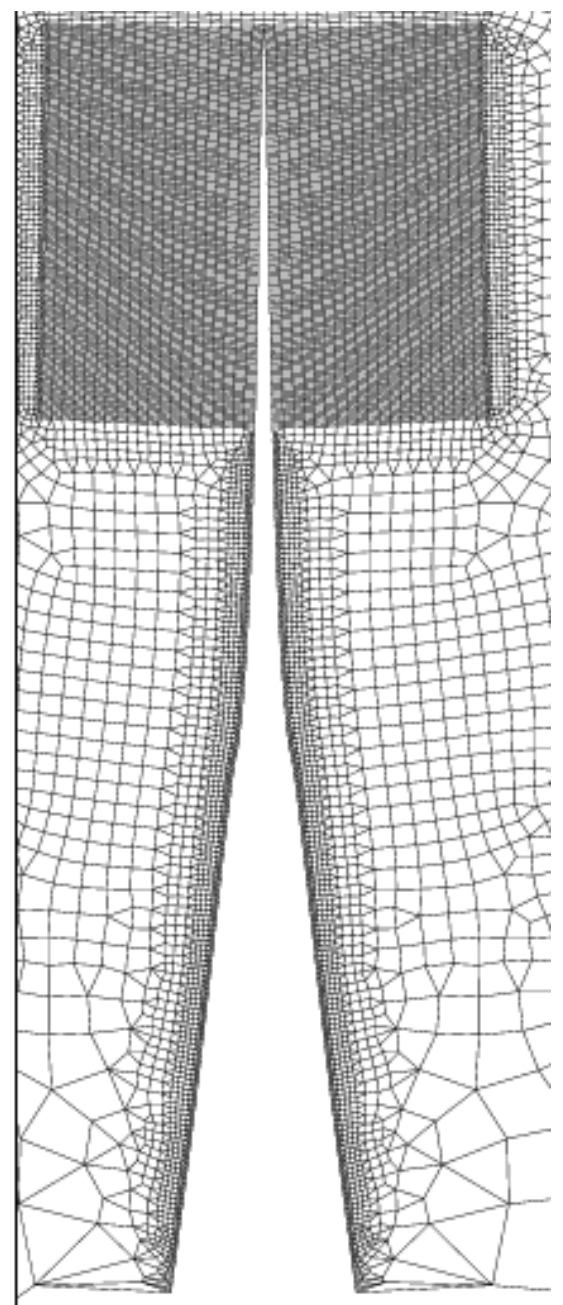

C

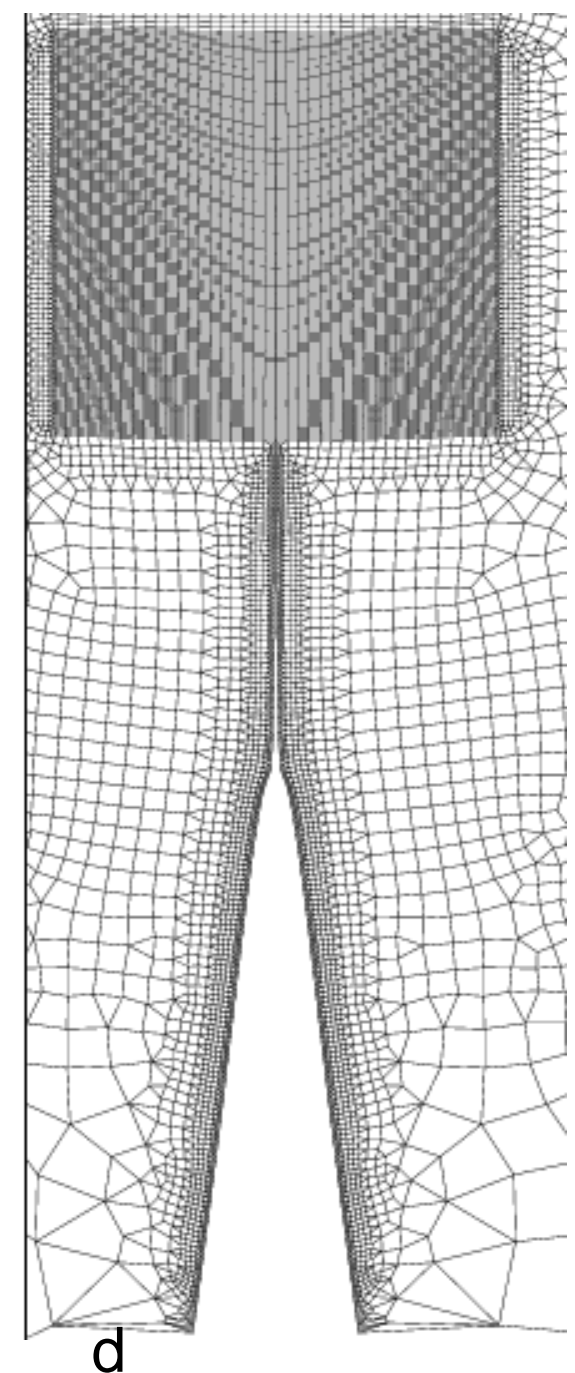

d

Figure 14 Finite element model a) Coarse mesh and boundary conditions b) c) refined and deformed meshes for the same load and bridged length, but b) $K_{n}=0$ c) $K_{n}=7 e 13 \mathrm{Nm}^{-3}$ and d) $K_{n}=1 e 15 \mathrm{Nm}^{-3}$ (see fig. 21a) 

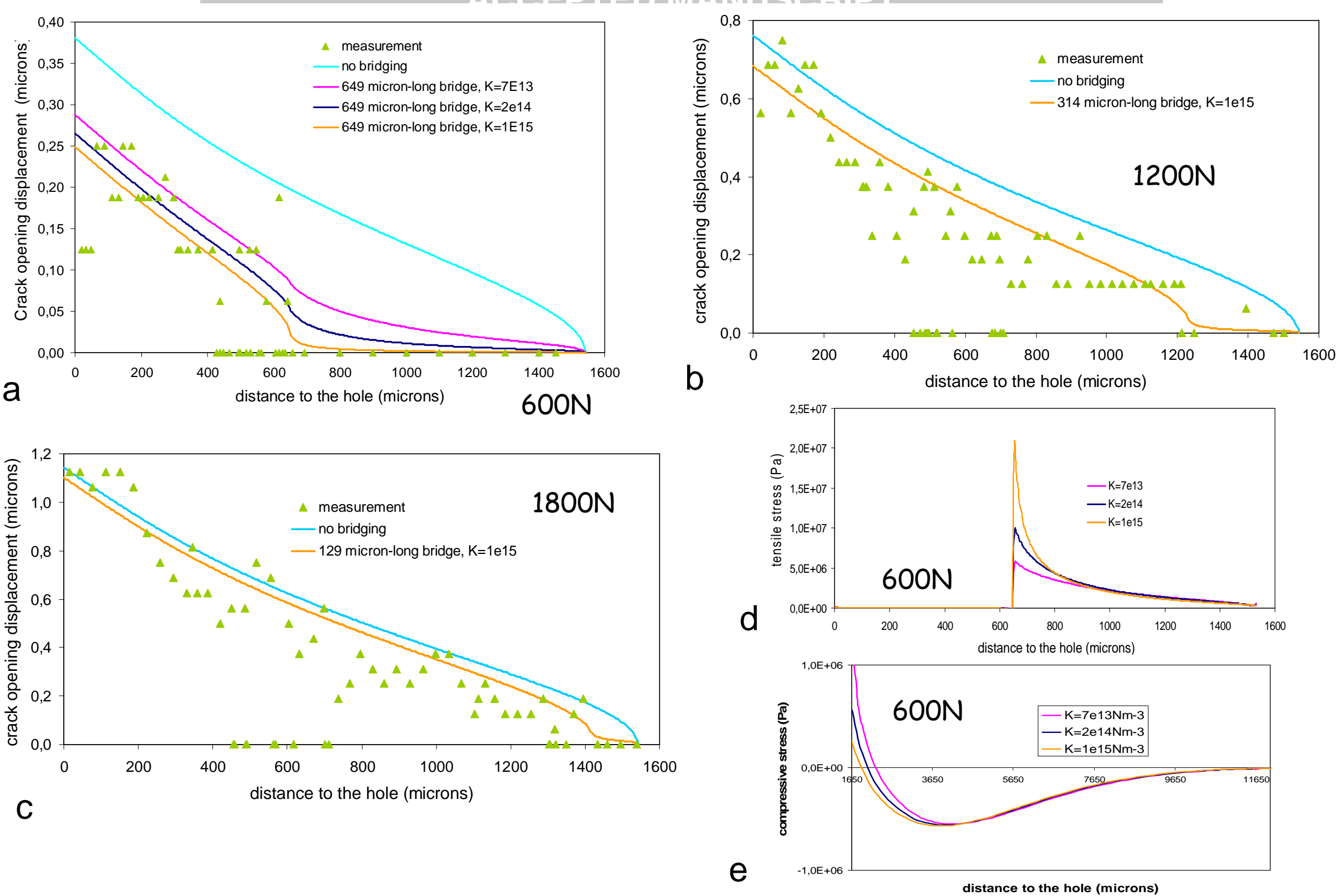

Figure 15: Measured and computed crack opening displacement profiles under a) $600 \mathrm{~N} \mathrm{b)} 1200 \mathrm{~N}, \mathrm{c}) 1800 \mathrm{~N}$ for a DCDC specimen vacuum annealed at $400^{\circ} \mathrm{C}$ during $240 \mathrm{~h}$. d) tensile stress along the crack face depending on the bridge stiffness, for $600 \mathrm{~N} \mathrm{e}$ ) compressive stress ahead of the bridged crack tip for $600 \mathrm{~N}$ 

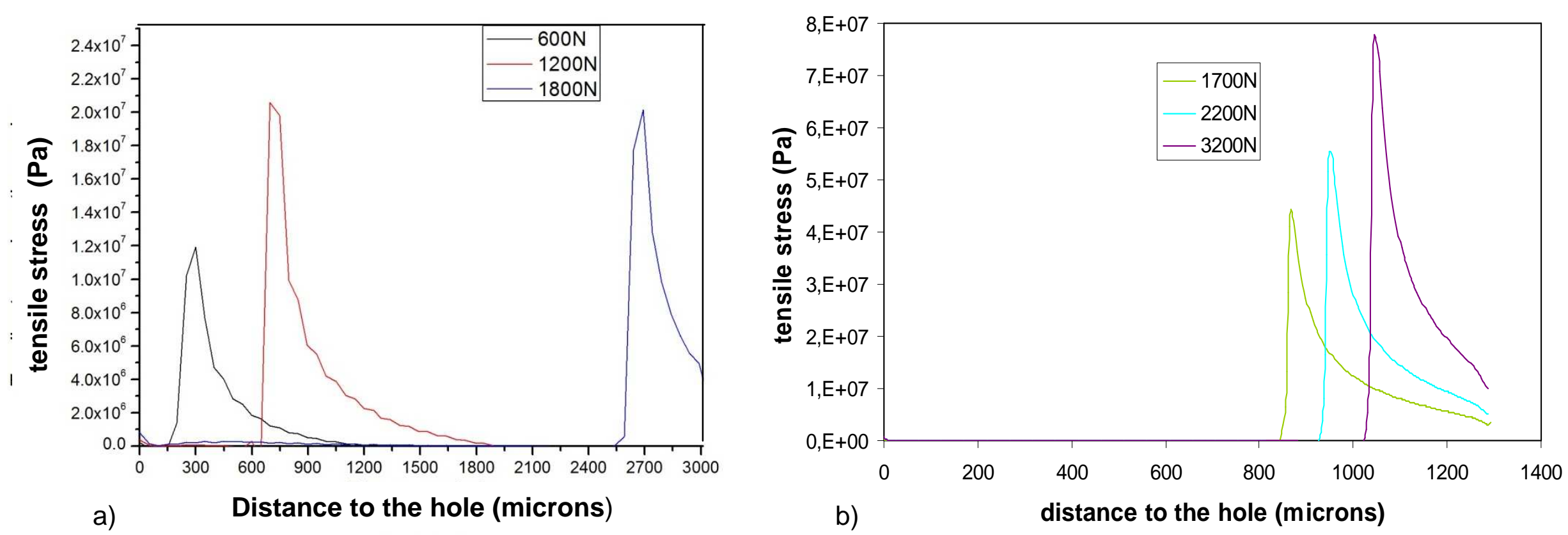

Figure 16: tensile stress profiles along partially bridged cracks a) in a DCDC specimen left 15 days at $90^{\circ} \mathrm{C}$ in a lixiviate and b) in a DCDC specimen left 11 days at $70^{\circ} \mathrm{C}$ in a lixiviate with $5 \mathrm{MPa}$ compression normal to the crack face 


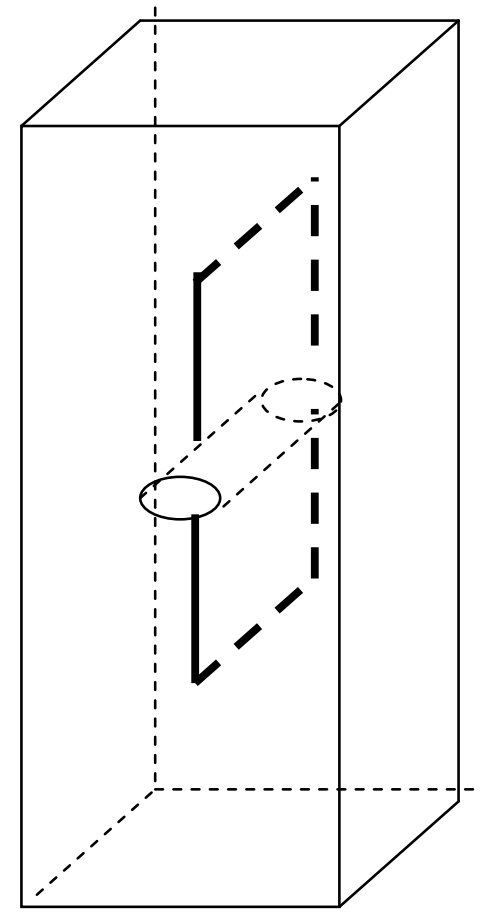

c)

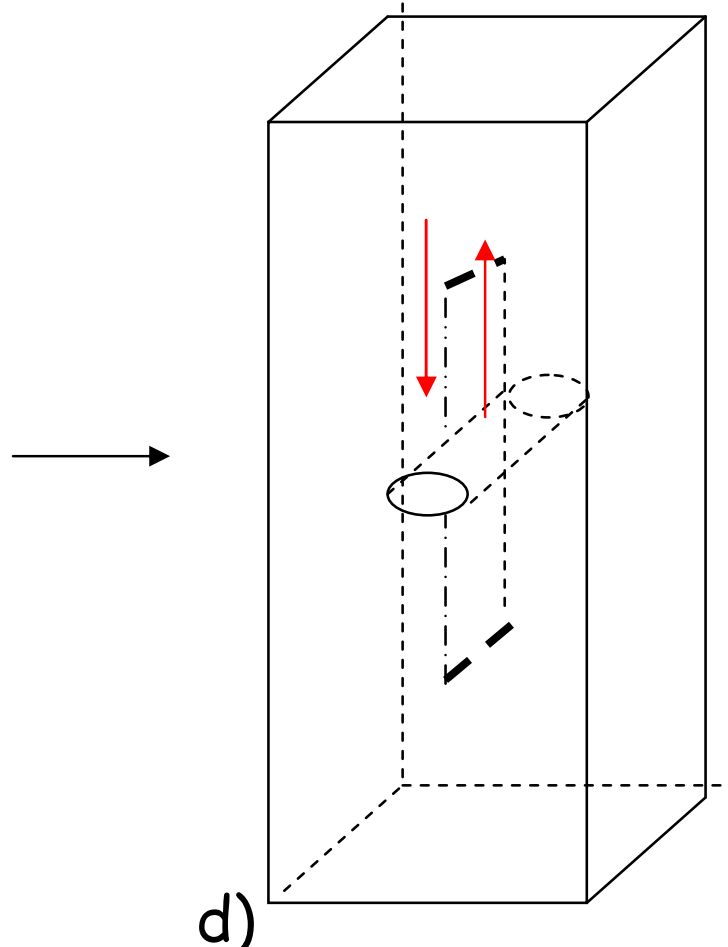

d) b)

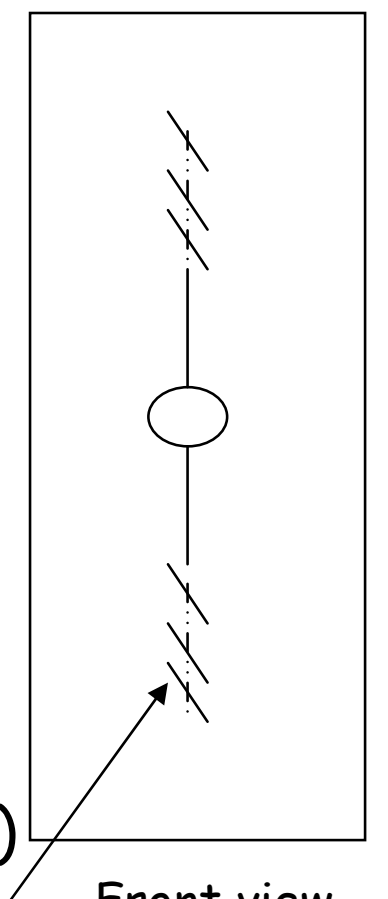

Front view

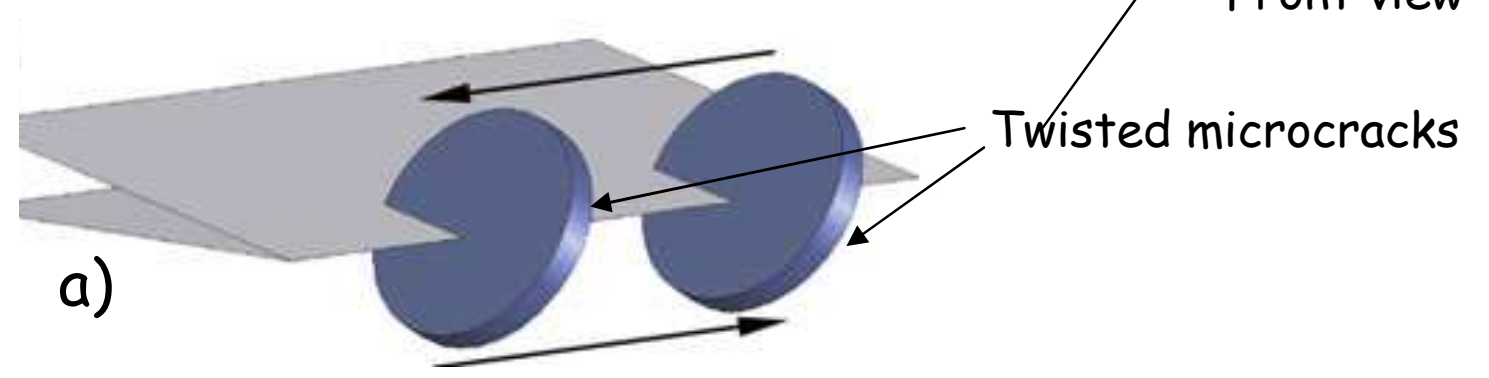

Figure 17: An interpretation of "en échelon" cracks shown on Fig. 9 as a result of inwards regression of a partially healed crack and mode III-induced initiation of twisted microcracks 


\section{Highligths}

Thermally induced crack healing in nuclear glass DCDC specimens was investigated.

Crack opening displacement profiles were measured in a SEM before/after annealing.

Healing was favoured by higher annealing temperatures and compressive normal stresses.

Compliant bridges formed between the crack face were modelled as interface elements.

A 15 days stay in water at $90^{\circ} \mathrm{C}$ was also efficient for crack healing.

Welding of glass plates was obtained after annealing above $425^{\circ} \mathrm{C}$ and $20 \mathrm{MPa}$ compression. 